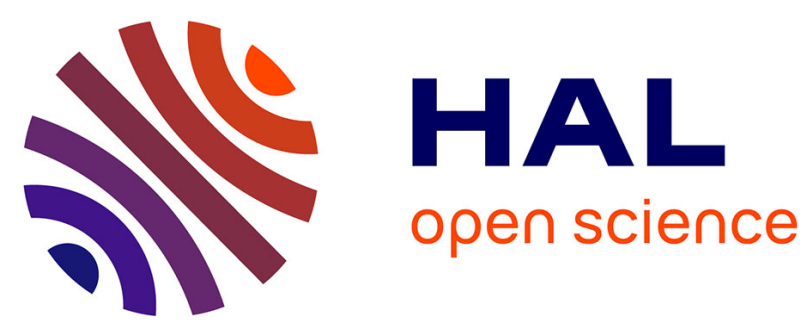

\title{
Quantitative measurement of atomic hydrogen in low-pressure methane flames using two-photon LIF calibrated by krypton
}

\author{
Nathalie Lamoureux, Kae Ken Foo, Pascale Desgroux
}

\section{To cite this version:}

Nathalie Lamoureux, Kae Ken Foo, Pascale Desgroux. Quantitative measurement of atomic hydrogen in low-pressure methane flames using two-photon LIF calibrated by krypton. Combustion and Flame, 2021, 224, pp.248-259. 10.1016/j.combustflame.2020.12.010 . hal-03099340

\author{
HAL Id: hal-03099340 \\ https://hal.science/hal-03099340
}

Submitted on 29 Oct 2021

HAL is a multi-disciplinary open access archive for the deposit and dissemination of scientific research documents, whether they are published or not. The documents may come from teaching and research institutions in France or abroad, or from public or private research centers.
L'archive ouverte pluridisciplinaire HAL, est destinée au dépôt et à la diffusion de documents scientifiques de niveau recherche, publiés ou non, émanant des établissements d'enseignement et de recherche français ou étrangers, des laboratoires publics ou privés. 


\section{Quantitative measurement of atomic hydrogen in low-pressure methane flames using two-photon LIF calibrated by Krypton}

Nathalie Lamoureux ${ }^{1}$, Kae Ken Foo ${ }^{1,2}$ and Pascale Desgroux ${ }^{1 *}$

\footnotetext{
Affiliation

${ }^{1}$ Univ. Lille, CNRS, UMR 8522 - PC2A - Physicochimie des Processus de Combustion et de l'Atmosphère, F-59000

Lille, France

${ }^{2}$ School of Mechanical Engineering, The University of Adelaide, Adelaide, SA 5005, Australia

*Corresponding author: Pascale Desgroux, pascale.desgroux@univ-lille.fr

lab. PC2A, bat. C11, Cité scientifique, 59655 Villeneuve d'Ascq, France,
} 


\begin{abstract}
In this work, the two-photon laser-induced fluorescence technique (TPLIF) was applied to measure the concentration profile of atomic hydrogen in low-pressure laminar premixed flames. Excitation of $\mathrm{H}$-atoms was performed by two-photon absorption at $205 \mathrm{~nm}$ and collecting the fluorescence at $656.3 \mathrm{~nm}$. For the first time in flames, the TPLIF signals from the H-atom have been calibrated using the TPLIF signal from krypton, directly seeded in the flame, excited at $204.13 \mathrm{~nm}$ and collecting the fluorescence at $826.5 \mathrm{~nm}$. This method was previously demonstrated in plasma environments and recently applied in our group to calibrate O-atom TPLIF signals using xenon as a standard gas. The calibration requires the measurements of TPLIF signals of $\mathrm{H}$ and $\mathrm{Kr}$ atoms in a flame, where the quenching rates can be determined from time-resolved LIF measurements. Given the short fluorescence lifetime of $\mathrm{H}$-atom, this last task was particularly challenging. A calibration flame was chosen to minimize collisions and the response time of the detection was determined using a deconvolution method. We found that the quenching rate is fairly constant around $4.6 \times 10^{8} \mathrm{~s}^{-1}$ at $5.3 \mathrm{kPa}$ in a large portion of the flame. The calculated quenching rate overestimates the measured value from $35 \%$ to $500 \%$ depending on the chosen assumption on the dependence of the quenching coefficient with temperature. The quantitative measurement of $\mathrm{H}$-atom mole fraction was carried out in three nitrogen-diluted low-pressure methane flames. The experimental profiles were compared with the calculated ones using chemical modeling. The variation in the experimental $\mathrm{H}$-atom mole fraction in the range of equivalence ratios agrees well with the simulated values. Quantitatively, the calculated mole fractions agree within 30\% with the experimental ones. The method is robust but its accuracy is limited by the uncertainty in the knowledge of the ratio of the two-photon cross-sections of $\mathrm{Kr}$ and $\mathrm{H}$ atoms. Application of this calibration method to atmospheric is discussed.
\end{abstract}

\title{
Keywords:
}

H-atom; Two-photon LIF; low-pressure flame; Krypton; calibration 


\section{Introduction}

Atomic species, in particular atomic hydrogen (H-atom), are involved in most elementary reactions of combustion chemistry. $\mathrm{H}$-atoms are mostly formed from fuel $\mathrm{H}$-abstraction, and participate in the dominant radical chain branching reaction, $(\mathrm{R} 1) \mathrm{H}+\mathrm{O}_{2} \rightleftharpoons \mathrm{O}+\mathrm{OH}$, and exothermic reaction $\left(\mathrm{OH}+\mathrm{CO} \rightleftharpoons \mathrm{H}+\mathrm{CO}_{2}\right)$ in flames. As with many small radicals, knowing their absolute concentration within the flame is important to better understand the kinetic reactions and detailed mechanisms. In stretched flames, the extinction strength rate and laminar flame speed directly interfere with these two reactions [1,2]. The reactions of formation and consumption of $\mathrm{H}$-atoms compete strongly depending on the flame strain rate.

Two main categories of techniques can achieve quantitative detection of atoms, in particular $\mathrm{H}$ atom. The first is based on molecular beam mass spectrometry (MBMS) after gas probe sampling. The second relies on optical detection. In MBMS experiments, $\mathrm{H}$-atom profiles were measured by ionizing $\mathrm{H}$-atom slightly above its appearance ionization potential [3-8]. The measurements were mainly carried out in laminar low-pressure premixed flames. The absolute quantification of atoms is performed assuming that partial equilibrium is reached in the burned gases $[3,6]$ or by applying the method of relative cross-sections for the ionization $[7,9]$. The absolute mole fraction of $\mathrm{H}$-atom is reported within a factor of two using either methods of quantification [10]. Unlike the aforementioned probe sampling technique, the in situ optical detection of $\mathrm{H}$ atom is non-intrusive. However, this method is challenging due to the $10 \mathrm{eV}$ gap between the ground and the first excited electronic states of atomic hydrogen. The single-photon excitation of $\mathrm{H}$ atom requires vacuum-ultraviolet radiation, which is strongly absorbed by most gases of the atmosphere, making it impractical in most combustion studies. Behind shock waves, this single absorption could be achieved by atomic resonance absorption spectroscopy (ARAS) [11-15], made possible by the specific configuration of the shock tube apparatus. The absolute concentration is then directly obtained from this absorption technique. The combination of ARAS/shock-tube is especially well suited for measuring the thermal dissociation rates of molecules of interest in combustion and producing $\mathrm{H}$ atoms or specific reaction rates involving the H-atom at high temperatures. Thus, Hanson's group measured the reaction rate constant of the reaction (R1) $\mathrm{H}+\mathrm{O}_{2}=\mathrm{OH}+\mathrm{O}$ [16]. In another context, Rennick et al. [17] were able to measure the population on level $n=2$ of $\mathrm{H}$ atom, largely populated due to the electronic excitation in 
their plasma. The calibration of the $\mathrm{H}$ atom concentration, probed at $656 \mathrm{~nm}$ (Balmer- $\beta, n=2 \rightarrow n=4)$ was carried out by using Cavity Ring-Down Spectroscopy (CRDS) in a $\mathrm{H}_{2} / \mathrm{Ar}$ arc jet discharge.

In plasma and flame environments, $\mathrm{H}$-atom is mainly detected using techniques involving a two-photon excitation from the ground state ( $n=1)$, such as two-photon laser induced polarization spectroscopy (TP-LIPS) [18-20] and two-photon laser induced fluorescence (TPLIF) [21-26]. Several other multi-photon excitation variants have also been proposed [24,27-29]. TP-LIPS is based on the direct measurement of the two-photon absorption, which gives it the advantage of not being affected by quenching. The technique has been applied in several plasma applications [18], and only in a few combustion environments [19,20,29]. We are indebted to Dux et al. [18] who have introduced an original way of calibrating the absolute density of the H-atom by using TP-LIPS from a standard response from xenon. The authors proposed to compare the two-photon absorption process of atomic hydrogen along the transition $(1 \mathrm{~S} \rightarrow 2 \mathrm{~S})$ at $243.2 \mathrm{~nm}$, and the one of xenon along the transition $5 p^{6} \rightarrow 5 p^{5} 6 p[1 / 2]_{0}$. This calibration method was later demonstrated in atmospheric flames by Grützmacher et al. [19]. It requires a removable xenon reference cell at room temperature. Even though it has a very interesting potential, the technique has only been used rarely in flames, maybe because of its complexity and, as pointed out by Grützmacher et al. [19], it is only accessible if pulsed UV laser radiation of sufficient peak power and single longitudinal mode spectral quality is available. In addition, the overlap configuration of the two required laser beams results in a long-length overlap volume, which in turn causes spatial averaging effects in flames. On the contrary, TPLIF at $205 \mathrm{~nm}$ is one of the most widespread methods for H-atom detection not only in flames [21-23,30-35], but also in plasmas [36-40]. It is a two-photon process between the states $n=1$ and $n$ $=3$ of $\mathrm{H}$-atom followed by the detection of fluorescence when it relaxes to the $n=2$ state at $656.3 \mathrm{~nm}$. Care must be taken to avoid interferences (photoionization, photolytic and photochemical effects $[31,41-46]$ ) and stimulated emission (SE) [21,47], which can each alter the linear relationship between the TPLIF signal and the atomic concentration. It was shown that the SE threshold is higher by using a ns-pulse laser compared to the shorter pulse lasers (ps or fs), while the photochemical effects (yielding to $\mathrm{H}$ formation) prevail with a longer pulse $[30,44]$. In the absence of these problems, the TPLIF signal should follow a quadratic regime with the laser energy. The TPLIF signal is then directly proportional to the atomic concentration, provided it has been 
corrected for the quenching rate $Q$. The quenching rate can be determined from the inverse of the fluorescence lifetime $\tau=1 /(A+Q)$ where $A$ is the total spontaneous emission rate of the excited state of $\mathrm{H}$-atom. However, due to its very short lifetime, the overall quenching rate is difficult to measure (especially when using a ns-pulse laser, and in atmospheric flames). Only few data obtained in low-pressure flames are reported [22]. Moreover, its calculation is obstructed by the lack of precise quenching cross-sections database determined at high temperatures $[48,49]$. Despite these difficulties, TPLIF has been recently reconsidered for measuring H-atom distributions in atmospheric flames (see eg. [32-35]). Except in [34], these studies used fs-lasers which may limit the impact of the quenching provided that they are combined with fast detections. Once measured, the TPLIF signals, corrected for quenching, can be converted into quantitative data. Only a few quantitative values of $\mathrm{H}$-atom concentration are reported in flames and plasmas. Most are obtained after a comparison with a known or calculated concentration of $\mathrm{H}$-atom measured in a separate set-up. Bittner et al. [22] converted the relative TPLIF signal in low-pressure $\mathrm{H}_{2} / \mathrm{O}_{2} / \mathrm{Ar}$ flames into an absolute $\mathrm{H}$-atom density, based on a calibration performed with the titration of $\mathrm{NO}_{2}$ in a flow-tube. Juchmann et al. [50] have calibrated the H-atom density from a calorimetric determination in a dc-arcjet. Wouters et al. [51] undertook the calibration of $\mathrm{H}$-atom density, from a time-resolved measurement of the fluorescence decay in a microwave discharge in $\mathrm{H}_{2}$. The TPLIF signal was also converted into an absolute $\mathrm{H}$-atom density from the comparison of the experimental signal obtained in a Hencken burner with kinetic calculations performed assuming an adiabatic equilibrium [33], or in a Bunsen burner with adiabatic flame calculations [45].

Goehlich et al. [52] have transposed the aforementioned method of calibration of TP-LIPS signals to atomic species detected by TPLIF by comparing their signal with that of a rare gas (xenon) at room temperature. Krypton has also been considered as a good candidate for the calibration, because it exhibits a two-photon resonance with excitation energies close to those of $\mathrm{H}$-atom and it presents a relative absorption cross-section half that of $\mathrm{H}$ according to Niemi et al. [37] and Boogaarts et al. [38]. The ratio of the two-photon absorption cross-sections of $\mathrm{Kr}$ and $\mathrm{Xe}$ was measured by Elliott et al. [53]. The calibration approach of $\mathrm{H}$-atom TPLIF signals has been widely applied in plasmas [37-40,54-57], however, to the best of our knowledge, never in flames. 
Following our previous study undertaken for O-atom calibration [58], the present work aims to measure the absolute concentration of atomic $\mathrm{H}$ species in flames previously stabilized in our laboratory. The absolute calibration of the H-atom requires a well-defined calibration flame where the H-TPLIF signal is directly related to that emitted by the noble gas, $\mathrm{Kr}$ according to $[37,38]$. In order to convert the relative signal into an absolute mole fraction, attention was paid to avoid interference effects or SE, and to the control of the quenching variation along the vertical axis of the flame. The experimental atomic hydrogen profiles were compared with the simulated ones by using the Premix code [59] with the detailed kinetic model developed in our laboratory [60].

\section{Experimental set-up}

\subsection{Low-pressure burner and gas supply}

Experiments were undertaken in laminar low-pressure methane flames stabilized on a 6-cm diameter bronze water-cooled McKenna burner. Temperature of the porous burner was stabilized at 293K and 333K in $\mathrm{N}_{2}$ and Ar diluted flames, respectively. The pressure is regulated within $\pm 0.3 \%$ by using an automatic valve (Oerlikon CMOVE/MOVE1250). The burner is mobile in translation in the vertical axis allowing the measurements of species profiles as a function of the height above the burner (HAB). Details about the burner and the gas supply were given in [61]. The volumetric gas flow rates of the studied flames were controlled with mass flow controllers (MFC). The values are reported in Erreur! Source du renvoi introuvable.. The premixed flames of $\mathrm{CH}_{4} / \mathrm{O}_{2}$ diluted in $\mathrm{N}_{2}$ and stabilized at $p=40$ Torr $(5.3 \mathrm{kPa})$ were identical to those reported in Refs. [58,60,61]. The role of the calibration flame diluted in $\mathrm{Ar}$ (named flame CH4_cal) (identical to the one selected in Ref. [58]) is explained in Sections 4 and 5. This flame was chosen so as to minimize the collisions as much as possible to allow the LIF decay rate measurements of $\mathrm{H}$ and $\mathrm{Kr}$ atoms. With a ns-laser, the decay rate was only accessible in sub-atmospheric flames. We could act on three parameters; (1) the pressure, (2) the nature of the diluent, and (3) the proportion of diluent. To achieve the best outcome, attention was paid to ensure the chosen flame was flat and stable. Following our previous work on O-atom calibration [58], the best compromise was found by stabilizing a stoichiometric argon-diluted methane flame at $p=2.8 \mathrm{kPa}$ (Table 1). Krypton gas (Air Products, purity 99.999\%) used for the calibration purpose was introduced into the chamber 
via the mixture gas line and its flow rate was controlled with a MFC (30 sccm, Bronkhorst, $\pm 0.5 \%$ ). Temperature profiles have been measured in these flames using NO-LIF thermometry $[58,60]$.

Table 1. Flame compositions. Gas flow rates are reported in slpm (at $273.15 \mathrm{~K}$ and $101.3 \mathrm{kPa}$ ). $\phi$ is the equivalence ratio.

\begin{tabular}{|l|l|l|l|l|l|l|}
\hline Flame & $p(\mathrm{kPa})$ & $\mathrm{CH} 4$ & $\mathrm{O}_{2}$ & $\mathrm{~N}_{2}$ & $\mathrm{Ar}$ & $\phi$ \\
\hline CH4 $(080)$ & 5.33 & $0.384 \pm 0.01$ & $0.96 \pm 0.02$ & $3.20 \pm 0.05$ & & 0.80 \\
\hline CH4(100) & 5.33 & $0.48 \pm 0.01$ & $0.96 \pm 0.02$ & $3.35 \pm 0.05$ & & 1.00 \\
\hline CH4(125) & 5.33 & $0.60 \pm 0.01$ & $0.96 \pm 0.02$ & $3.29 \pm 0.05$ & & 1.25 \\
\hline CH4_cal & 2.80 & $0.36 \pm 0.01$ & $0.72 \pm 0.02$ & & $2.95 \pm 0.05$ & 1.00 \\
\hline
\end{tabular}

\subsection{Laser set-up}

The pulsed laser system consisted of a frequency-doubled Nd:YAG laser (Powerlite DLS8000, Continuum) pumping a dye laser (ND6000, Continuum) providing radiation at $615 \mathrm{~nm}$, with a repetition rate of $10 \mathrm{~Hz}$. The fundamental frequency of the dye laser was doubled using a KDP crystal. The doubled and the residual fundamental beams were mixed in a BBO crystal to generate a $205 \mathrm{~nm}$ radiation. The $205 \mathrm{~nm}$ beam was separated from the doubled and the residual beams using four Pellin-Broca prisms. The laser bandwidth of the doubled frequency was determined to be $0.16 \mathrm{~cm}^{-1}$ at $305 \mathrm{~nm}$ from previous works and is estimated to be around $0.15-0.2 \mathrm{~cm}^{-1}$ at $205 \mathrm{~nm}$. Typically, the maximum output laser energy was $150 \mu \mathrm{J} /$ pulse. It was adjusted using a variable attenuator consisting a polarizer at $205 \mathrm{~nm}$ and a half-wave plate (EKSMA) and monitored with an energy sensor (J-10MB-HE, Coherent). The laser beam was directed to the burner after being focused by a $500 \mathrm{~mm}$ focal length lens. For a laser energy of $100 \mu \mathrm{J} /$ pulse, the laser fluence in the volume of measure was estimated to be $50 \mathrm{~mJ} / \mathrm{cm}^{2}$. The collection set-up was identical to that previously described in [58]. The LIF signal was collected at $f / 4$ by a two-achromatic lenses system $(f=200 \mathrm{~mm}, 650-1050 \mathrm{~nm})$ and focused onto the entrance slit of a spectrometer (SP2300i, Acton Research) with a $150 \mathrm{gr} / \mathrm{mm}$ grating blazed at $500 \mathrm{~nm}$. The entrance slit ( $250 \mu \mathrm{m}$ width, $6 \mathrm{~mm}$ height) was parallel to the laser axis. The exit slit was adjusted to collect the fluorescence emission with a bandwidth of $15 \mathrm{~nm}$. In this study, two photomultiplier tubes (PMT) were used for the time-resolved LIF measurements. The PMT R2257 (Hamamatsu) has a spectral sensitivity covering the 
$300-900 \mathrm{~nm}$ spectral range and is well suited to capture the fluorescence from $\mathrm{H}$ and $\mathrm{Kr}$. Unfortunately, the risetime of this PMT is relatively long (2.6 ns). Hence, a faster PMT (R2059 Hamamatsu, 1.3 ns rise time) was also used. However, its sensitivity range does not extend beyond $650 \mathrm{~nm}$, prohibiting the measurement of $\mathrm{Kr}-$ LIF. As explained in Section 4, the combination of LIF measurements using these two PMTs allows the determination of fluorescence decay rates in the low-pressure flames listed in Table 1. The LIF signals were recorded using a digital oscilloscope (HDO4000, 12-bit vertical resolution, $1 \mathrm{GHz}$ bandwidth, $1.25 \mathrm{GS} / \mathrm{s}$, LeCroy), transferred to a PC in real-time for processing using a Labview program. The information of the laser wavelength provided by a laser control software was recorded simultaneously. The efficiency of the LIF collection systems was spectrally measured using a uniform radiance calibrated source (CSTM-LR-6-M, SphereOptics). The ratio of these efficiencies $\left(C_{\mathrm{Kr}} / C_{\mathrm{H}}\right)$ at the two wavelengths $(826.5$ and $656.3 \mathrm{~nm})$ was measured to be equal to 0.14 . The occurrence of stimulated emission (SE) was controlled in the forward direction along the laser axis at the wavelength of the fluorescence transitions (656 and $826.5 \mathrm{~nm}$ ) using a fast photodiode (Thorlabs, DET10A02), in front of which a BK7 glass was placed to reject the $205 \mathrm{~nm}$ light, similarly to $[30,44]$ but without a filter.

\section{Method for absolute calibration of TPLIF signals of atomic hydrogen}

According to [37,52], the H-atom TPLIF signal can be converted into an absolute mole fraction by intercomparing with the TPLIF signal of krypton. In this section, we present the spectroscopy of $\mathrm{H}$ and $\mathrm{Kr}$ atoms and the related spectroscopic constants and coefficients, which are required for the quantitative measurement of $\mathrm{H}$-atom concentration. Then, we briefly explain the basic equations, which were used to obtain the concentration from the LIF signals of $\mathrm{H}$ and $\mathrm{Kr}$ atoms.

\subsection{Spectroscopy of $\mathrm{H}$ and $\mathrm{Kr}$ atoms}

The two species exhibit similar excitation energy diagrams as shown in 


\section{List of Figure captions}

Fig. 1. For convenience, the excited state is noted later $(n=3)$, the state on which the fluorescence is collected is noted ( $n=2)$, the spontaneous emission rate from level $(n=3)$ to level $(n=2)$ is $A_{32, \mathrm{i}}$ and the total spontaneous rate of level $(n=3)$ is $A_{3, \mathrm{i}}$ for $\mathrm{i}=\mathrm{H}, \mathrm{Kr}$. Atomic hydrogen is excited from the ground state $\left(1 \mathrm{~s}^{2} \mathrm{~S}_{1 / 2}\right)$ up to the state $n=3$ at $97492 \mathrm{~cm}^{-1}$ via a two-photon absorption at $205.145 \mathrm{~nm}$. The TPLIF signal is detected along the transition from $n=3$ to $n=2$ states at $656.3 \mathrm{~nm}($ Balmer $\alpha)$. The fine structure of the atomic hydrogen is well documented (see e.g. Refs. $[48,62-65]$ ) and is summarized in the Supplementary Materials where the reader will find among other a discussion about the radiative lifetime and the spontaneous emission rate of the excited level $n=3$. The spectroscopy of krypton is quite complex, but is well documented, see for example the ASC database from the NIST $[62,66,67]$. Krypton is excited from the ground state $\left(4 \mathrm{p}^{6}{ }^{1} \mathrm{~S}_{0}\right)$ to the excited level $5 \mathrm{p}^{\prime}{ }^{1} \mathrm{D}_{2}\left(4 \mathrm{p}^{5}\left({ }^{2} P_{1 / 2}^{0}\right) 5 \mathrm{p}^{2}[3 / 2] j=2\right)$ at $97945.16 \mathrm{~cm}^{-1}$ via a two-photon absorption at $204.13 \mathrm{~nm}$. The TPLIF signal is collected at $826.5 \mathrm{~nm}$ along the transition from $5 \mathrm{p}^{, 1} \mathrm{D}_{2}$ to $5 \mathrm{~s}{ }^{1} \mathrm{P}_{1}\left(4 \mathrm{p}^{5}\left({ }^{2} \mathrm{P}_{1 / 2}^{0}\right) 5 \mathrm{~s}^{2}[1 / 2]_{0} j=1\right)$ states.

As pointed out in the Supplementary Materials, uncertainties persist in determining the spontaneous rates for both species and this would certainly deserve further work. For $\mathrm{H}$, in agreement with [37,57], we have measured a radiative lifetime of about $17 \mathrm{~ns}$ (Section 4.3). We have chosen to use the calculated value of $A_{3, \mathrm{H}}$ $=5.78 \times 10^{7} \mathrm{~s}^{-1}$ (corresponding to a radiative lifetime of $17.3 \mathrm{~ns}$ ) in the equations described below. According to the selection rules, the ratio $A_{32} / A_{3}$ for $\mathrm{H}$-atom is equal to 1 . For $\mathrm{Kr}$, the total spontaneous emission rate was measured to be $3.5 \times 10^{7} \mathrm{~s}^{-1}$, which agrees with the recommendations from the NIST. The spectroscopic constants required for the calibration procedure are listed in Table 2 and are those recommended by the NIST. This table also reports the value of the ratio of the two-photon absorption cross-sections between $\mathrm{Kr}$ and $\mathrm{H}$ from the level $(n=1)$ to the level $(n=3)$ (see Section 3.2.2).

Table 2. Spectroscopic parameters for $\mathrm{H}$ and $\mathrm{Kr}$ adopted in the present work. The spontaneous emission rates follow the recommendations from the NIST $[64,67]$. 


\begin{tabular}{|c|l|l|}
\hline & $\mathrm{H}$ & $\mathrm{Kr}$ \\
\hline$\sigma_{\mathrm{Kr}}^{<2>} / \sigma_{\mathrm{H}}^{<2>}$ & $0.62 \pm 50 \%[37]$ \\
\hline$A_{3}\left(10^{7} \mathrm{~s}^{-1}\right)$ & $5.78[64]$ & $3.50[67]$ \\
\hline$A_{32}\left(10^{7} \mathrm{~s}^{-1}\right)$ & $5.78[64]$ & $3.42[67]$ \\
\hline
\end{tabular}

\subsection{Principle of the calibration}

According to Goehlich et al. [52], the time integrated TPLIF signal of atom i collected by the PMT $\left(S_{i}\right)$ can be expressed as follows:

$$
S_{\mathrm{i}}=C_{\mathrm{i}} \sigma_{\mathrm{i}}^{\langle 2\rangle} g\left(\Delta \bar{v}_{\mathrm{i}}\right) G^{\langle 2\rangle} \frac{A_{32, \mathrm{i}}}{A_{3, \mathrm{i}}+Q_{\mathrm{i}}} f_{\mathrm{B}}(T)[\mathrm{i}]\left(\frac{I_{v_{\mathrm{i}}}}{h v_{\mathrm{i}}}\right)^{2}
$$

where $C_{\mathrm{i}}$ is the global efficiency of the LIF collection at a given wavelength (PMT, spectrometer, lenses, solid angle, volume of measure), $\sigma_{\mathrm{i}}^{\langle 2\rangle}$ is the lineshape-independent two-photon absorption cross-section, $g\left(\Delta \bar{v}_{\mathrm{i}}\right)$ is the normalized line profile of the two-photon excitation which is composed of the convolution of the effective laser line profile and the atomic absorption line, $G^{\langle 2\rangle}$ is the photon statistical factor (equal to 2 ). $A_{32, \mathrm{i}}$ is the spontaneous emission rate along the detection transition (from level $n=3$ to $n=2$ ), $A_{3, \mathrm{i}}$ is the total spontaneous emission rate of the excited level, $Q_{\mathrm{i}}$ is the total quenching rate, $A_{3, \mathrm{i}}+Q_{\mathrm{i}}$ is the total depopulation rate of the level $n=3$ or the fluorescence decay rate. The ratio $A_{32, \mathrm{i}} / A_{3, \mathrm{i}}+Q_{\mathrm{i}}$ is the fluorescence quantum yield. [i] is the concentration of the species i, $f_{\mathrm{B}}(T)$ is the temperature-dependent Boltzmann function of the probed level of the ground state. The ratio $I_{v_{\mathrm{i}}} / h v_{\mathrm{i}}$ represents the number of photons per time unit at a given frequency $v_{\mathrm{i}}$, where $I_{v_{\mathrm{i}}}$ is the laser intensity.

The calibration process involves the comparison of the TPLIF signals of $\mathrm{H}$ and $\mathrm{Kr}$ collected in a calibration flame seeded with a known mole fraction of Krypton $\left(\chi_{\mathrm{Kr}}\right)$. These signals are measured by tuning the laser wavelength around each atomic transition while the fluorescence signal is collected by selecting the spectrometer wavelength at the appropriate value (656 and $826 \mathrm{~nm}$ for $\mathrm{H}$ and $\mathrm{Kr}$, respectively). Provided that 
the quadratic regime of fluorescence holds (see Section 5.1 and the Supplementary Materials), and according to $[37,38,52]$, the $\mathrm{H}$-atom mole fraction $\left(\chi_{\mathrm{H}}\right)$ can be calculated from the following equation:

$$
\chi_{\mathrm{H}}=\chi_{\mathrm{Kr}} \frac{C_{\mathrm{Kr}}}{C_{\mathrm{H}}} \frac{\sigma_{\mathrm{Kr}}^{<2>}}{\sigma_{\mathrm{H}}^{<2>}} \frac{A_{32, \mathrm{Kr}}}{A_{3, \mathrm{Kr}}+Q_{\mathrm{Kr}}} \frac{A_{3, \mathrm{H}}+Q_{\mathrm{H}}}{A_{32, \mathrm{H}}} \frac{g\left(\Delta \bar{v}_{\mathrm{Kr}}\right)}{g\left(\Delta \bar{v}_{\mathrm{H}}\right)} \frac{S_{\mathrm{H}}}{S_{\mathrm{Kr}}} \frac{I_{\nu_{\mathrm{Kr}}}^{2}}{I_{\nu_{\mathrm{H}}}^{2}}\left(\frac{\nu_{\mathrm{H}}}{v_{\mathrm{Kr}}}\right)^{2}
$$

The Boltzmann function $f_{\mathrm{B}}$ of each species whose ground state is a singlet state $\mathrm{S}$ is equal to 1 , independent of the temperature. The adopted spectroscopic parameters for this work are reported in Table .

The ratio of the absorption cross-sections between $\mathrm{Kr}$ and $\mathrm{H}\left(\sigma_{\mathrm{Kr}}^{<2>} / \sigma_{\mathrm{H}}^{<2>}\right)$ is a critical value for the calibration. Its determination was performed in a flow-tube reactor by comparing the TPLIF signals of $\mathrm{H}$ and $\mathrm{Kr}$, while the $\mathrm{H}$ atoms were quantified using $\mathrm{NO}_{2}$ titration method [37,38]. Although different values of the spectroscopic parameters for $\mathrm{H}$ were adopted in these two studies, their ratio $\sigma_{\mathrm{Kr}}^{<2>} / \sigma_{\mathrm{H}}^{<2>}$ differs only by $10 \%$ with 0.62 in [37] and 0.56 in [38]. Mainly due the experimental limitations, the uncertainties of $\sigma_{\mathrm{Kr}}^{<2>} / \sigma_{\mathrm{H}}^{<2>}$ are quite large with $\pm 50 \%$ for both studies. In this work, we have adopted the value of 0.62 as reported in Table 2 . Equation (2) also reveals that the calibration requires a correction for the variation in the fluorescence quantum yields between the two species. It is especially challenging when a ns-laser is used in the current study to determine the relatively fast total fluorescence decay rates $A_{3, \mathrm{i}}+Q_{\mathrm{i}}$ of the excited state $(n=3)$ of the two species. In the following section, we present both the experimental and the mathematical procedure developed to determine the quenching rates $Q_{\mathrm{i}}$. Finally, if the linewidths of the two resonances (of the $\mathrm{H}$ and $\mathrm{Kr}$ transitions for example) are different, it is necessary either to integrate the fluorescence signal over the resonance transitions or the ratio $g\left(\Delta \bar{v}_{\mathrm{Kr}}\right) / g\left(\Delta \bar{v}_{\mathrm{H}}\right)$ must be determined. This latter determination being generally imprecise, the fluorescence signal was therefore spectrally integrated by scanning the laser wavelength over the resonance of each species following the recommendations of Goehlich et al. [52].

\section{Quenching rates}

One of the main difficulties in the calibration procedure lies in the evaluation of the quenching rate of the two atoms $(\mathrm{H}$ and $\mathrm{Kr})$ in Eq. 2. The quenching rate is defined by $Q_{\mathrm{i}}=N_{\mathrm{t}} \sum_{\mathrm{n}} \chi_{\mathrm{n}} k_{\mathrm{n}}^{\mathrm{i}}$ where $N_{\mathrm{t}}$ is the total density, $\chi_{\mathrm{n}}$ is the collider mole fraction and $k_{\mathrm{n}}^{\mathrm{i}}$ is the quenching coefficient that is equal to the product between the 
quenching cross-section $\sigma_{\mathrm{n}}^{\mathrm{i}}$ and the relative mean speed $\left\langle v_{\mathrm{n}, \mathrm{i}}\right\rangle=\sqrt{8 k_{\mathrm{B}} T / \pi \mu} . \mu$ is the reduced mass, $k_{\mathrm{B}}$ is the Boltzmann constant and $T$ is the temperature.

The quenching coefficients of the main colliders of interest in flames are available in the literature $[37,48,49,57,69-71]$. However most of them were measured at room temperature from TPLIF experiments in flow tubes in which the atoms ( $\mathrm{H}$ or $\mathrm{Kr}$ ) and the selected species (collider), of known concentration, collide. In flames, the only accessible measurement is the overall quenching coefficient corresponding to the complex flame chemical composition mixture $\sum_{\mathrm{n}} \chi_{\mathrm{n}} k_{\mathrm{n}}^{\mathrm{i}}$. Therefore, it is complicated to extract individual cross-section at high temperatures. Only a few works report estimated quenching cross-sections, in particular for $\mathrm{H}_{2} \mathrm{O}$ [49]. Ultra-short laser pulses offer the possibility to measure accurately the effective quenching rate in a large range of flame conditions from the LIF decay-time, providing a fast detection is used. Using a complex but promising fs pump-probe approach, Wang et al. [72] could determine the effective lifetime of the excited-state $\mathrm{H}$ atoms in atmospheric $\mathrm{H}_{2} /$ air flames. They report lifetimes of a few ps only. Otherwise, in the other studies using ps or fs excitation $[30,33,44,45]$ the quenching rates of $\mathrm{H}$ atom were estimated based on the cross sections data available in the literature $[37,48,49,69,70]$. Different strategies were followed to consider the temperature dependence of the collisional process. The temperature dependence of the quenching cross section is often set at $\mathrm{T}^{-0.5}$ for most colliders except for $\mathrm{H}_{2} \mathrm{O}$ for which a $\mathrm{T}^{-1}$ dependence of the cross section is selected, see e.g. $[33,45]$. Despite the efforts in the above-mentioned studies to correct for quenching variations in flames, important uncertainties persist in determining the quenching rates. Therefore, so far, the best approach to determine the quenching rate of $\mathrm{H}$ and $\mathrm{Kr}$ is through the measurement of the LIF decay rate, whenever possible. The quenching determination is possible only under a limited range of flame conditions in which the fluorescence lifetime is sufficiently long compared to the response function of the detector and to the laser pulse duration. It turns out that the limiting factor for the quenching measurements required in Eq. 2 is the very short lifetime of the excited state of $\mathrm{H}$-atom (around $2 \mathrm{~ns}$ in nitrogen-diluted flames at $p=5.33 \mathrm{kPa}$ ). This contrasts our previous work dedicated to O-atom calibration using Xe, where the lifetime of the noble gas was the limiting factor [58]. 
Considering the characteristics of our experimental set-up (laser, spectral response of the PMT, fall time of the PMT), the reliability of the quenching (or total decay rate) determination is crucial for the calibration, as detailed in Section 5. The procedure first relies on the calibration of the concentration of $\mathrm{H}$-atoms relative to that of $\mathrm{Kr}$ in a chosen flame. This is performed by using the PMT R2257, covering the required spectral range of collection. The chosen flame, called the calibration flame, was selected to minimize the collisions as much as possible to allow the LIF decay rate measurements. Second, the value of $\mathrm{H}$-atom concentration in the calibration flame is used to calibrate the values of H-atom in the other flames using the PMT R2059 (offering a faster fall time than the R2257).

\subsection{Determination of fluorescence decay rates using a deconvolution method}

The use of nanosecond-laser is limiting our ability to resolve accurately the quenching lifetimes. It is especially challenging at higher pressures, where the effective lifetimes are comparable to the response time of the PMT. To understand the constraints posed by different detection devices, two PMTs (R2059 and R2257) were used to record the TPLIF signal of H-atom under a range of pressures. Since the fluorescence lifetimes are of the same order of magnitude as the laser pulse duration, we used the multi-exponential deconvolution technique to extract the fluorescence lifetime. Following the work of van Gessel et al. [73] and Schmidt et al. [74], the detected H-TPLIF signal is a convolution of the effective decay rate and the excitation rate of the excited state, which is given by the square of the laser pulse intensity. The laser pulse profile is determined from the time-resolved Rayleigh signal measured at $615 \mathrm{~nm}$ (close to the wavelength of $\mathrm{H}$-atom fluorescence). Figure 2 presents an example of the squared laser pulse shape along with the H-TPLIF signal decay measured using PMT R2257. Instead of using the square of the measured laser pulse profile, a best-fitted mathematical form of the squared laser pulse profile was used, which is a gaussian function convoluted with a single-exponential decay function. The H-TPLIF signal is then fitted using a convolution of the simulated square of the laser pulse profile and an exponential decay function, from which the fluorescence decay rate $\left(A_{3, \mathrm{i}}+Q_{\mathrm{i}}\right)$ is determined. The excitation rate of the excited state is considered via including the squared laser pulsed profile in the fitting. The fitting procedure excluded the fluorescence decay lower than $20 \%$ of the peak value to avoid the influence of the signal rebound from the PMTs. 
Figure 3 shows the variation of the decay rates $\left(A_{3, \mathrm{H}}+Q_{\mathrm{H}}\right)$ of $\mathrm{H}$-atom as a function of pressure (SternVolmer plot) obtained in a stoichiometric $\mathrm{CH}_{4} / \mathrm{O}_{2}$ flame diluted with $58 \% \mathrm{~N}_{2}$ for the two PMTs. Using this approach, it is estimated that the maximum measurable decay rates are around $40 \times 10^{7} \mathrm{~s}^{-1}$ and $25 \times 10^{7} \mathrm{~s}^{-1}$ by using PMT R2059 and R2257, respectively, which correspond to minimum fluorescence lifetimes of about 2.5 and 4 ns, for these PMTs (see also next section). Below the lowest limit (i.e. with the PMT R2257), the same variation of the fluorescence decay rate was found using the two PMTs.

\subsection{Stern-Volmer plots and discussion}

Stern-Volmer plots were obtained in the burned gases of the two stoichiometric flames for $\mathrm{H}$-atom and in the calibration flame for $\mathrm{Kr}$-atom. The composition of each flame was kept constant (identical to those of the flames CH4(100) and CH4_cal, Table 1) while varying its pressure over its accessible stability range. It is assumed that the chemical composition and the temperature in the burned gases remains constant with pressure, so the quenching should increase linearly with pressure. Depending on the flame, the pressure studied ranged from 1.1 to $9.0 \mathrm{kPa}$. The fluorescence decay rates of $\mathrm{Kr}$ were measured with the PMT R2257 (Fig. 4). Those of H-atom were measured with the PMT R2257 (Fig. 5a) and with the PMT R2059 (Fig. 5b).

\subsubsection{Krypton}

A certain percentage of the Ar diluent was replaced by $\mathrm{Kr}$ in the premixed gases to maintain constant the total dilution rate of the flame. The amount of $\mathrm{Kr}$ was adjusted in order to avoid the occurrence of SE as shown in the Supplementary Materials (Fig. S1). With $35 \mu \mathrm{J} /$ pulse, this threshold occurred for Kr concentration greater than $10^{15}$ molecules $/ \mathrm{cm}^{3}$ at flame temperature, which turns into $1.5 \times 10^{14}$ molecules $/ \mathrm{cm}^{3}$ only at room temperature. The data presented in Fig. 4 were obtained with $0.5 \% \mathrm{Kr}$ in mole fraction. $\left(A_{\mathrm{i}}+Q_{\mathrm{i}}\right)$ follows a linear increase. The y-intercept was fixed to $3.5 \times 10^{7}$ (Table 2). To our knowledge, this is the first Stern-Volmer plot of $\mathrm{Kr}$ obtained in a flame environment.

\subsubsection{H-atom}


The Stern-Volmer plots (Fig. 5) of $\mathrm{H}$ were obtained in the same way as for Kr. The final objective is to measure the fluorescence decay rate in the flames stabilized at $p=5.33 \mathrm{kPa}$ in which the absolute concentration of $\mathrm{H}$-atom is needed for modeling purposes (Section 5). The y-intercept was fixed to $5.78 \times 10^{7} \mathrm{~s}^{-1}$ (Table 2). These plots reach a "plateau" region with the PMT R2257 where fluorescence decay rates are greater than $25 \times$ $10^{7} \mathrm{~s}^{-1}$. In contrast, the PMT R2059 is fast enough to provide reliable fluorescence decay rates up to at least 40 $\times 10^{7} \mathrm{~s}^{-1}$. However, the signal to noise ratio (SNR) is higher with the PMT R2257 leading to less dispersed results than with the R2059. The SNR was estimated to 70 with the R2257 and to 7 with the R2059 from the excitation spectrum of $\mathrm{H}$ atom in the burned gases of the calibration flame. Therefore, in certain cases, the PMT R2257 is preferable depending on the measurements.

The slopes obtained in these experiments are gathered in Table 3. They were determined by considering only the values of the fluorescence decay rates lower than the limits indicated in each figure, which are associated with the overall response time of the detectors. The slopes obtained for H-atom with the two PMTs agree to within $10 \%$, which gives confidence in the determination of the fluorescence decay rates in particular up to $40 \times 10^{7} \mathrm{~s}^{-1}$ with the fast PMT. From the obtained slopes, one determines the quenching rates and the fluorescence lifetimes as listed in Table 3. The overall quenching rate in each flame is determined by multiplying the slope with the pressure (in Pa). It corresponds to $N_{\mathrm{t}}\left(\sum_{\mathrm{n}} \chi_{\mathrm{n}} k_{\mathrm{n}}^{\mathrm{H}}+\chi_{\mathrm{dil}} k_{\mathrm{dil}}^{\mathrm{H}}\right)$ with the dil index referring to the diluent ( $\mathrm{Ar}$ or $\mathrm{N}_{2}$ ) and the $n$ index referring to the species in the burned gases other than the diluent. The $\mathrm{CH} 4(100)$ nitrogen-diluted flame has an overall quenching rate which is 3.8 times that of the argon-diluted CH4_cal flame. Its determination required a slight extrapolation of value of the slope beyond the total decay rate of $40 \times 10^{7} \mathrm{~s}^{-1}$ and is therefore considered as reliable. Since these flames have a similar dilution ratio, which implies a similar overall gas composition, the difference in the quenching between argon and nitrogen diluted flames is mainly due to the higher quenching coefficient of nitrogen relatively to argon at flame temperatures. At room temperature, the ratio of these coefficients is measured to be between 5 and $6.6[37,48,69]$. The quenching rate measured in the flame $\mathrm{CH} 4(100)$ at $25 \mathrm{~mm} \mathrm{HAB}\left(4.63 \times 10^{8} \mathrm{~s}^{-1}\right)$ was compared with the one calculated using: $Q_{\mathrm{i}}=N_{\mathrm{t}} \sum_{\mathrm{n}} \chi_{\mathrm{n}} k_{\mathrm{n}}^{\mathrm{i}}=N_{\mathrm{t}} \sum_{\mathrm{n}} \chi_{\mathrm{n}} \sigma_{\mathrm{n}}^{\mathrm{i}} \sqrt{8 k_{\mathrm{B}} T / \pi \mu}$. For this determination we used the flame composition of the major species $\chi_{\mathrm{n}}$ given by flame modeling (section 5), the flame temperature $T$ and the 
quenching coefficients measured at room temperature [69]. Several extrapolations of the quenching cross section value at flame temperature were used: assuming an invariance of $\sigma_{\mathrm{n}}^{\mathrm{i}}$ with $\mathrm{T}$ leads to an overall quenching rate equals to $21.5 \times 10^{8} \mathrm{~s}^{-1}$, i.e. nearly 5 times higher than that measured; assuming an invariance of the quenching coefficients $k_{\mathrm{n}}^{\mathrm{i}}$ with $T$ (i.e. corresponding to a dependence of the quenching cross section set at $\mathrm{T}^{-0.5}$ ) leads to $Q_{\mathrm{H}}=8.4 \times 10^{8} \mathrm{~s}^{-1}$ i.e. $80 \%$ higher than that measured; finally, introducing an exception for $\mathrm{H}_{2} \mathrm{O}$ with a dependency in $\mathrm{T}^{-1}$ leads to $Q_{\mathrm{H}}=6.2 \times 10^{8} \mathrm{~s}^{-1}$. This last approach was notably followed in [33,45] and gives the results closest to that measured although still overestimated by $35 \%$.

The evaluation of the quenching cross sections assumptions, made possible thanks to the overall quenching measurements achieved in this work, underlines the need of better understand the variation in quenching cross sections with temperature. Particularly the lack of an accurate and complete database of quenching coefficients at flame temperatures prevents the achievement of precise absolute $\mathrm{H}$-atom measurements in flames as pointed out by $[32,45]$. This pitfall must be kept in mind in case where the H-atom moles fractions are compared between flames on the basis of the ratio between their TP-LIF signals. Only if the flames have similar temperatures, diluents and dilution ratios, the error should be limited.

Table 3: Slopes $\left(\times 10^{4} \mathrm{~s}^{-1} / \mathrm{Pa}\right)$ of the Stern-Volmer plots, quenching rates $\left(\times 10^{8} \mathrm{~s}^{-1}\right)$ and fluorescence lifetimes (ns) obtained for $\mathrm{Kr}$ and $\mathrm{H}$ atoms (with the two PMTs)

\begin{tabular}{|c|c|c|c|c|c|c|c|c|}
\hline Flame & $\begin{array}{c}p \\
(\mathrm{kPa})\end{array}$ & $\begin{array}{c}\text { Slope } \\
\mathrm{Kr} \\
(\mathrm{R} 2257)\end{array}$ & $\begin{array}{c}\text { Quenching } \\
\text { rate Kr } \\
(\mathrm{R} 2257)\end{array}$ & $\begin{array}{c}\text { Kr-atom } \\
\text { fluorescence } \\
\text { lifetime (ns) }\end{array}$ & $\begin{array}{c}\text { Slope } \\
\mathrm{H} \\
(\mathrm{R} 2257)\end{array}$ & $\begin{array}{c}\text { Slope } \\
\mathrm{H} \\
(\mathrm{R} 2059)\end{array}$ & $\begin{array}{c}\text { Quenching } \\
\text { rate H } \\
\text { (R2059) }\end{array}$ & $\begin{array}{c}\text { H-atom } \\
\text { fluorescence } \\
\text { lifetime (ns) }\end{array}$ \\
\hline CH4(100) & 5.33 & & & & 7.68 & 8.66 & 4.63 & 1.9 \\
\hline CH4_cal & 2.80 & 1.49 & 0.417 & 13 & 4.76 & 4.36 & 1.22 & 5.6 \\
\hline
\end{tabular}

\subsection{Quenching profile}

Equation 1 shows that there is a linear relationship between the TPLIF signal $S_{\mathrm{H}}$ and the product of the atom concentration $[\mathrm{H}]$ with the fluorescence quantum yield $\frac{A_{32, \mathrm{H}}}{A_{3, \mathrm{H}}+Q_{\mathrm{H}}}$. Even though the absolute quenching determination is difficult in flames, especially in atmospheric flames, the knowledge of the ratio between $S_{\mathrm{H}}$ and the fluorescence quantum yield is very useful to convert the TPLIF profile along the flame into the relative profile of $\mathrm{H}$-atom concentration. Figure 6 shows the profile of the fluorescence decay rate of the H-atom in the flame CH4_cal and of the relative H-atom mole fraction (determined in Section 5). Due to the limited SNR, the 
measurements of the decay time were only accessible after $5 \mathrm{~mm} \mathrm{HAB}$, thus covering almost all the $\mathrm{H}$ profile from its early onset to the burned gases. Here, the comparison of the fluorescence decay rates measured by the two PMTs shows that the values are found to be in good agreement, but the standard deviation of $Q$ is higher with the PMT R2059 (8\%) due a weaker SNR than with the PMT R2257 (3\%). Except in the early reaction zone, where $A_{3, \mathrm{H}}+Q_{\mathrm{H}}$ shows a $25 \%$ decrease from the burner surface, the fluorescence decay rate then remains almost constant from 9 to $35 \mathrm{~mm}$ around $19.7 \times 10^{7} \mathrm{~s}^{-1}$, i.e from the second half of the $\mathrm{H}$-atom gradient to the burned gases. The same behavior was found in the four premixed flames investigated in this work. Therefore, the variation in the quenching along the flames is neglected in the following (Section 5).

\section{Absolute concentration profiles of $\mathbf{H}$-atom}

\subsection{Quantification of TPLIF signal in the calibration flame}

TPLIF measurements require that some conditions to be fulfilled. Particularly, Eq. 2 used in the calibration procedure implicitly relies on the fact that photolytic effects, photoionization and stimulated emission (SE) are very limited if not absent. If such, a quadratic regime is effectively reached. The LIF signals plotted against the laser energy on a logarithmic scale makes it easy to verify the fluorescence regime. These plots were performed for $\mathrm{H}$ and $\mathrm{Kr}$ atoms and provided in Fig. S2 of the Supplementary Materials. A slope equals to 2.08 was found with a laser energy up to $50 \mu \mathrm{J} /$ pulse for the $\mathrm{H}$-atom and $1 \%$ of $\mathrm{Kr}$ in the calibration flame. This condition on the value of the slope is necessary but not sufficient to attest the conditions abovementioned, additional tests were therefore carried out. In this energy range, SE was not observed with either $\mathrm{H}$ or $\mathrm{Kr}$ atom. On the contrary, SE was identified in the presence of higher $\mathrm{Kr}$ concentrations as reported in Fig. S1. A significant sub-linearity of the LIF quadratic regime for $\mathrm{Kr}$ was reported in $[38,56]$, where the $\mathrm{Kr}$ concentration was 1 or 3 orders of magnitude higher than the threshold value for the SE occurrence observed in the present work. In the present work, care was undertaken in all the investigated flames to avoid any saturation of the LIF signal, by controlling the occurrence of SE not only as a function of the laser energy but also with the total concentration of $\mathrm{Kr}$ in the flame (see Fig. S1). In addition, the absence of photolytic effects was checked 
by comparing the profiles of the $\mathrm{H}$ atoms obtained at different laser energies $(50-135 \mu \mathrm{J} / \mathrm{pulse})$ as shown in Fig. S3. Such effects have already been identified as a cause of deformation in the LIF profile $[42,43]$.

Finally, measurements were performed at $35 \mu \mathrm{J} /$ pulse for all the calibration procedures, and at $50 \mu \mathrm{J} /$ pulse for the measurements of the atomic hydrogen profiles in $\mathrm{N}_{2}$-diluted flames, thus insuring the conditions required for application of Eq. 2.

Implementation of the calibration procedure requires that the normalized line profiles $g\left(\Delta \bar{v}_{\mathrm{i}}\right)$ to be known for $\mathrm{Kr}$ and $\mathrm{H}$-atom (Eq. [2]). Since such determination is generally imprecise, the fluorescence signal was therefore spectrally integrated by scanning the laser wavelength over the resonance of each species following the recommendations of Goehlich et al. [52].

Finally, the H-atom quantification was carried out by alternately measuring the time and spectrally integrated TPLIF signals from $\mathrm{H}$ and $\mathrm{Kr}$ in the burned gases $(\mathrm{HAB}=21 \mathrm{~mm})$ of flame CH4_cal. This flame was seeded with $1 \% \mathrm{Kr}$ (in mole fraction) during $\mathrm{Kr}$-TPLIF measurement. The laser intensity was maintained constant ( $35 \mu \mathrm{J} /$ pulse) at each excitation wavelength while the collection wavelength of the spectrometer was appropriately adjusted. One can mention that the TPLIF signal measured for $\mathrm{Kr}$ was typically 7 times lower than the H-TPLIF. The fluorescence was collected by using the PMT R2257, and corrected for the collection efficiency at the two wavelengths $(826.5$ and $656.3 \mathrm{~nm}$ ) (see Section 2.2). This PMT is fast enough to allow reliable fluorescence decay rate measurements in the calibration flame (Section 4). The fluorescence decay rate, measured with the PMT R2257, $A_{3, \mathrm{H}}+Q_{\mathrm{H}}$ of $\mathrm{H}$-atom was found to be $19.1 \times 10^{7} \mathrm{~s}^{-1}$, i.e. 2.5 times higher than that

for $\operatorname{Kr}$ (which was found to be $7.67 \times 10^{7} \mathrm{~s}^{-1}$ ). Considering the spectroscopic parameters (Table 2) and Eq. 2, the $\mathrm{H}$-atom mole fraction was calculated to be $3.58 \%$ at $\mathrm{HAB}=21 \mathrm{~mm}$. The accuracy was estimated to be $\pm 65 \%$, considering the standard deviation of the measurements $(9 \%)$, the ratio of the fluorescence decay rates $(4 \%)$, the accuracy of the $\mathrm{Kr}$ mole fraction $(2 \%)$ and the ratio of the two-photon absorption cross-section $( \pm 50 \%)$ [38].

\subsection{H-atom mole fraction profiles in the $\mathrm{N}_{2}$ diluted flames}

H-atom mole fraction profiles were obtained as follows: first, the relative profiles of the TPLIF signal were measured in the flames stabilized at $p=5.33 \mathrm{kPa}$ (Table 1) and in the calibration flame, then the 
quantitative intercomparison of the TPLIF signals between flames was carried out at $21 \mathrm{~mm}$ HAB. Finally, the mole fraction of $\mathrm{H}$-atom in the calibration flame was used to calibrate the other flames. As explained in Section 3.2, the TPLIF signals were temporally and spectrally integrated during the intercomparison between flame CH4_cal and flame CH4(100). However, during the intercomparison between the nitrogen-diluted flames (all stabilized at $p=5.3 \mathrm{kPa}$ ) and along the flame axis, the signals were only integrated over time, because of the negligible lineshape variation. The TPLIF profiles were recorded with the PMT R2257, which provides a higher SNR. But the intercomparison of the signals between the flames at $p=2.8$ and $5.3 \mathrm{kPa}$ was done by using the faster PMT R2059 in order to determine the fluorescence decay rate in the nitrogen-diluted flames at $p=5.3$ $\mathrm{kPa}$, which needs to be introduced in the Eq. 3 see below.

In the last step of the procedure, the absolute mole fraction of the $\mathrm{H}$-atom is determined at $21 \mathrm{~mm} \mathrm{HAB}$ from the absolute $\mathrm{H}$-atom mole fraction in the flame $\mathrm{CH}_{4} \_$cal at the same $\mathrm{HAB}\left(\chi_{\mathrm{H}, \mathrm{cal}}=3.58 \%\right.$ at $\left.21 \mathrm{~mm}\right)$ and using Equation 3:

$$
\chi_{\mathrm{H}}=\chi_{\mathrm{H}, \mathrm{cal}} \frac{T p_{\mathrm{cal}}}{T_{\text {cal }} p} \frac{A_{\mathrm{H}}+Q_{\mathrm{H}}}{A_{\mathrm{H}, \mathrm{cal}}+Q_{\mathrm{H}, \mathrm{cal}}} \frac{g\left(\Delta \bar{v}_{\mathrm{cal}}\right)}{g(\Delta \bar{v})} \frac{S_{\mathrm{H}}}{S_{\mathrm{H}, \mathrm{cal}}} \frac{I_{\mathrm{cal}}^{2}}{I^{2}}
$$

where $T$ and $p$ are temperature and pressure in the flames. The index cal refers to the calibration flame. Then, the absolute mole fraction in the nitrogen-diluted flames was determined with an overall uncertainty of $75 \%$, considering the standard deviation (10\%) during the intercomparison between the flames, and the accuracy of the $\mathrm{H}$-atom mole fraction determined in the calibration flame (65\%). As pointed out above, this uncertainty is mostly due to the original uncertainty reported during the measurement of the ratio of the two-photon absorption cross-sections $( \pm 50 \%)$. Despite this great uncertainty, it should be noted that the determination of the variation of the $\mathrm{H}$ atom mole fraction between the studied low-pressure flames is very accurate $(10 \%)$ from the twophoton LIF measurement corrected for quenching.

The resulting mole fraction profiles of $\mathrm{H}$-atom in the flames stabilized at $p=5.33 \mathrm{kPa}$ are presented in Fig. 7 along with the profiles simulated using NOMecha2.0 mechanism [60]. Simulations were performed with Premix code [59] using the experimental temperature profiles measured in situ by NO-LIF thermometry [60]. Considering the experimental uncertainties, the experimental $\mathrm{H}$-atom profiles are found to be in a general good 
agreement with the simulated ones. In particular, after normalization (see Fig. S3), the onset and the gradient are well predicted except in the rich flame $\mathrm{CH} 4(125)$ where the simulated gradient is found to be downstream of the experimental one $(1 \mathrm{~mm})$. Similar to what was observed in the O-atom measurements in [58] in the same flames, the experimental profiles decrease in the burned gases (for HAB $>10-12 \mathrm{~mm}$ ) contrary to the flatness of the simulated profiles. The non-reproduction of the decay of the simulated mole fractions of the $\mathrm{O}$ and $\mathrm{H}$ atoms in the burned gases was confirmed using other chemical mechanisms as shown in Fig. S4 in the Supplementary Materials. Interestingly, the discrepancy in the simulated H-atom mole fractions is as large as $40 \%$ at $25 \mathrm{~mm}$ in case of flame $\mathrm{CH} 4(080)$. The origin of this discrepancy between the experimental and the simulated profiles is beyond the scope of this work but deserves to be further investigated.

At $25 \mathrm{~mm} \mathrm{HAB}$, the experimental $\mathrm{H}$-atom mole fraction is $30 \%$ higher than the simulated values but is still within the overall uncertainty. However, the relative variation of the $\mathrm{H}$-atom mole fraction with the flame richness is found to agree well (within 10\%) with the simulated one as shown in the Supplementary Materials (Fig. S5).

As indicated in the introduction, a few papers calibrate the atomic mole fractions assuming that partial equilibrium is reached in the burned gases. We have also evaluated this approach to quantify the $\mathrm{H}$-atom mole fraction in the burned gases of the three nitrogen-diluted flames listed in Table 1 and discuss it in comparison with the calibration method developed in this paper. In the burned gases $(15<\mathrm{HAB} / \mathrm{mm}<25)$, the temperature variation is weak (within $50 \mathrm{~K}$ ) in all flames. A slight increase of the temperature in function of HAB is observed in the stoichiometric flame, and a slight decrease in the two other flames [60]. The species concentrations, especially those involved in fast bimolecular reactions, are expected to reach equilibrium values. The $\mathrm{H}$ mole fractions have been calculated according to the equilibrium constant of the following three reactions where $\mathrm{H}$ atoms are involved: (R1) $\mathrm{H}+\mathrm{O}_{2} \rightleftharpoons \mathrm{OH}+\mathrm{O},(\mathrm{R} 2) \mathrm{O}+\mathrm{H}_{2} \rightleftharpoons \mathrm{OH}+\mathrm{H}$, and (R3) $\mathrm{OH}+\mathrm{H}_{2} \rightleftharpoons \mathrm{H}_{2} \mathrm{O}+\mathrm{H}$. Using the equilibrium constant and the measured temperatures, the $\mathrm{H}$-atom mole fraction can be determined at each $\mathrm{HAB}$ from:

$$
\begin{aligned}
& \chi_{H}=\frac{1}{K_{1}} \frac{\chi_{O} \chi_{O H}}{\chi_{O_{2}}} \\
& \chi_{H}=K_{2} \frac{\chi_{O} \chi_{H_{2}}}{\chi_{O H}}
\end{aligned}
$$




$$
\chi_{H}=K_{3} \frac{\chi_{O H} \chi_{H_{2}}}{\chi_{H_{2} O}}
$$

where $K_{\mathrm{i}}$ is the equilibrium constant and $\chi_{\mathrm{i}}$ is the species mole fraction. The mole fraction values of $\mathrm{OH}, \mathrm{H}_{2}$, $\mathrm{H}_{2} \mathrm{O}$ are issued from the flame modeling, while the $\mathrm{O}$ atom mole fractions previously measured [58] are adopted. The experimental O-atoms mole fractions were also found to diminish in the burned gas while the simulated ones are constant [58]. Figure 8 shows, in the burned gases region, the comparison between the experimental $\mathrm{H}$-atom mole fractions $\chi_{\mathrm{H}}$ with the calculated ones. As for the experimental profiles, the $\mathrm{H}$-atom mole fractions calculated using Eq. 4 and Eq. 5 are found to decrease in function of HAB. Using Eq. 6 the H-atom mole fraction is nearly constant in flames $\mathrm{CH} 4(080)$ and (100) but shows a slight increase in the rich flame $\mathrm{CH} 4(125)$. The relative variations of $\mathrm{H}$-atom mole fraction with equivalence ratio at $25 \mathrm{~mm} \mathrm{HAB}$, calculated using Eq. 4-6, are reported in Fig. S5. A very good agreement is found between the present experimental results, the predictions from the detailed kinetic simulation and the equilibrium calculations based on Eq. 4 and Eq. 5 where the experimental O-atom mole fractions are considered (Fig. S5). Using Eq. 6, the discrepancies are larger. Globally the $\mathrm{H}$-atom mole fraction determination at $25 \mathrm{~mm} \mathrm{HAB}$ assuming partial equilibrium give consistent results with the current experiments as shown in Fig. 8. The calculated mole fraction at $25 \mathrm{~mm}$ is less than $30 \%$ weaker than the experimental value, affected as noted previously by a large uncertainty. Additional in situ measurements of $\mathrm{OH}$ would be of great interest for a better understanding of this detailed kinetics in the burned gases region.

\section{Conclusions}

In this work, the two-photon laser induced fluorescence technique was applied to measure the concentration profiles of atomic hydrogen in laminar low-pressure premixed flames. Excitation of the transition from its ground state to state $n=3$ was performed by two-photon absorption at $205 \mathrm{~nm}$ and collecting the fluorescence from $n=3$ to $n=2$ at $656.3 \mathrm{~nm}$. For the first time in flames, the TPLIF signals from the H-atom have been calibrated by using the TPLIF signal from krypton, excited at $204.13 \mathrm{~nm}$ and collecting the fluorescence at $826.5 \mathrm{~nm}$. This calibration method is inspired by the work of Dux et al. [18], who calibrated their two-photon polarization spectroscopy signal of O-atom formed in a discharge using a standard response 
from xenon. The use of a standard was later demonstrated by Goehlich et al. [52] to calibrate their TPLIF signal of O-atom in a discharge with xenon. To our knowledge, our work is the first demonstration of calibrating the TPLIF signal of H-atom in flames by using a noble gas. Similar to what we did in the calibration of the absolute concentration of O-atoms in flames using Xe [58], our approach advantageously introduces krypton directly into the studied flames, unlike the calibration of the two-photon polarization spectroscopy signal from the Hatom produced in atmospheric flames [19] and based on the use of xenon in a separate reference cell at room temperature.

To implement this calibration, it was necessary to measure the TPLIF signals of $\mathrm{H}$ and $\mathrm{Kr}$ atoms in a flame, where the quenching rates could be determined from time-resolved LIF measurements. Due to the short fluorescence lifetime of $\mathrm{H}$-atom, this last task was particularly challenging, especially with the equipment available in our laboratory. Indeed, our tunable laser provides ns-pulses and our PMTs have fall times of the order of a few ns. Thus, it required a calibration flame to be chosen to minimize collisions and to thoroughly assess the response time of the detection using a deconvolution method. The procedure advantageously combines the complementary performances of two PMTs and has been found suitable for measuring the fluorescence decay-times in our low-pressure flames $(p=2.8$ and $5.3 \mathrm{kPa})$. We found that the quenching rate is fairly constant from the second half of the $\mathrm{H}$-atom mole fraction gradient to the burned gases. In the early reaction zone, with low $\mathrm{H}$-atom mole fractions, the quenching rate was found to increase towards burner surface but only by $25 \%$. This result indicates that the distribution of $\mathrm{H}$-atoms in a given laminar premixed flame can be reasonably obtained by neglecting the quenching rate variation in most of the flame. Then, we have transposed the room-temperature quenching coefficients from the literature to flame temperature conditions to calculate the quenching rate following different assumptions. The deviation between the calculated and the measured value of the overall quenching ranges from $35 \%$ to $500 \%$. This indicates that care should be taken when correcting TPLIF signals with the quenching coefficients measured at room temperature.

The quantitative measurement of $\mathrm{H}$-atom mole fraction was carried out in three nitrogen-diluted lowpressure methane flames of different equivalence ratios $(\phi)$ and extensively investigated in our laboratory, in particular for the prompt-NO formation [60]. The experimental profiles were compared with the calculated ones using chemical modeling. The $70 \%$ increase in the experimental $\mathrm{H}$-atom mole fraction from $\phi=0.8$ to 1.25 is 
well reproduced by modeling within $10 \%$, as well as the position of the concentration gradients. However, in the burned gases, the calculated mole fraction has a flat profile unlike the experimental ones which tends to decrease. The $\mathrm{H}$-atom mole fraction profiles have been simulated using different detailed mechanisms, indicating that the discrepancy between all the simulated values was as large as $40 \%$. In these flames, the reliability of the partial equilibrium assumption to calculate the H-atom mole fraction was evaluated. The equilibrium calculations from the reactions (R1) $\mathrm{H}+\mathrm{O}_{2} \rightleftharpoons \mathrm{OH}+\mathrm{O}$ and (R2) $\mathrm{O}+\mathrm{H}_{2} \rightleftharpoons \mathrm{OH}+\mathrm{H}$ where the experimental O-atom mole fractions obtained in [58] was used led to similar results as the detailed kinetic simulations. Quantitatively, the calculated mole fractions using equilibrium or the detailed kinetic simulation agree within $30 \%$ with the experimental ones, which is a good result but attenuated considering that the error bar is $75 \% .50 \%$ of the uncertainty arises from the determination of the ratio of the two-photon absorption crosssections of $\mathrm{Kr}$ and $\mathrm{H}[37,38]$. While the calibration procedure used in this work is effectively demonstrated, the contribution of this work to refine the H-atom chemistry in flames is limited by the large uncertainty in the cross-section ratio, which would certainly deserve further investigation.

This uncertainty unfortunately constitutes a limiting factor so that the calibration method can compete with the usual methods based on an a priori estimate of the absolute mole fraction calculated in a reference flame in which adiabatic conditions or partial equilibrium are reached. It is nevertheless attractive because it can be considered in other flames or environments for which indirect calibration is not possible. For example, a major interest is to transpose the calibration procedure to atmospheric flames, where $\mathrm{H}$-atom can be measured by TPLIF with fs-lasers. To conclude the calibration procedure using TPLIF from krypton is an accurate method and very promising if it is possible to reduce the uncertainty on the ratio of the absorption cross sections.

\section{Acknowledgments}

This work is a contribution to the CPER research project CLIMIBIO. The authors thank the French Ministère de l'Enseignement Supérieur et de la Recherche, the Hauts-de-France Region and the European Funds for Regional Economical Development for their financial support to this project. 
SMM.pdf file 


\section{References}

[1] S. Dooley, M. Uddi, S.H. Won, F.L. Dryer, Y. Ju, Methyl butanoate inhibition of n-heptane diffusion flames through an evaluation of transport and chemical kinetics, Combust. Flame. 159 (2012) 1371-1384.

[2] A.E. Long, R.L. Speth, W.H. Green, Numerical investigation of strained extinction at engine-relevant pressures: Pressure dependence and sensitivity to chemical and physical parameters for methane-based flames, Combust. Flame. 202 (2019) 318-333.

[3] J.C. Biordi, Molecular beam mass spectrometry for studying the fundamental chemistry of flames, Prog. Energy Combust. Sci. 3 (1977) 151-173.

[4] D.A. Knyazkov, A.G. Shmakov, O.P. Korobeinichev, Application of molecular beam mass spectrometry in studying the structure of a diffusive counterflow flame of $\mathrm{CH} 4 / \mathrm{N} 2$ and $\mathrm{O} 2 / \mathrm{N} 2$ doped with trimethylphosphate, Combust. Flame. 151 (2007) 37-45.

[5] C. Douté, J.-L. Delfau, R. Akrich, C. Vovelle, Experimental study of the chemical structure of lowpressure premixed n-heptane-O2-Ar and iso-octane-O2-Ar flames, Combust. Sci. Technol. 124 (1997) 249-276.

[6] A. Bhargava, P.R. Westmoreland, MBMS analysis of a fuel-lean ethylene flame, Combust. Flame. 115 (1998) 456-467.

[7] M. Schenk, L. Leon, K. Moshammer, P. Oßwald, T. Zeuch, L. Seidel, F. Mauss, K. Kohse-Höinghaus, Detailed mass spectrometric and modeling study of isomeric butene flames, Combust. Flame. 160 (2013) 487-503.

[8] J. Bian, J. Vandooren, P.J. Van Tiggelen, Experimental study of the formation of nitrous and nitric oxides in $\mathrm{H}_{2} / \mathrm{O}_{2} / \mathrm{Ar}$ flames seeded with $\mathrm{NO}$ and/or $\mathrm{NH}_{3}$, Symp. Int. Combust. 23 (1991) 379-386.

[9] T.A. Cool, K. Nakajima, C.A. Taatjes, A. Mcllroy, P.R. Westmoreland, M.E. Law, A. Morel, Studies of a fuel-rich propane flame with photoionization mass spectrometry, Proc. Combust. Inst. 30 (2005) 16811688.

[10] A.M. Dmitriev, D.A. Knyazkov, T.A. Bolshova, A.G. Tereshchenko, A.A. Paletsky, A.G. Shmakov, O.P. Korobeinichev, Structure of CH4/O2/Ar flames at elevated pressures studied by flame sampling molecular beam mass spectrometry and numerical simulation, Combust. Flame. 162 (2015) 3946-3959.

[11] K. Thielen, P. Roth, Resonance absorption measurements of N, O, and H atoms in shock heated HCN/O2/Ar mixtures, Combust. Flame. 69 (1987) 141-154.

[12] C. Xu, M. Braun-Unkhoff, C. Naumann, P. Frank, A shock tube investigation of $\mathrm{H}$ atom production from the thermal dissociation of ortho-benzyne radicals, Proc. Combust. Inst. 31 (2007) 231-239.

[13] S.L. Peukert, R. Sivaramakrishnan, M.-C. Su, J.V. Michael, Experiment and theory on methylformate and methylacetate kinetics at high temperatures: Rate constants for $\mathrm{H}$-atom abstraction and thermal decomposition, Combust. Flame. 159 (2012) 2312-2323.

[14] L. Golka, I. Weber, M. Olzmann, Pyrolysis of dimethoxymethane and the reaction of dimethoxymethane with H atoms: A shock-tube/ARAS/TOF-MS and modeling study, Proc. Combust. Inst. 37 (2019) 179187.

[15] R.K. Hanson, Applications of quantitative laser sensors to kinetics, propulsion and practical energy systems, Proc. Combust. Inst. 33 (2011) 1-40.

[16] D.A. Masten, R.K. Hanson, C.T. Bowman, Shock tube study of the reaction hydrogen atom + oxygen .fwdarw. hydroxyl + oxygen atom using hydroxyl laser absorption, J. Phys. Chem. 94 (1990) 7119-7128.

[17] C.J. Rennick, R. Engeln, J.A. Smith, A.J. Orr-Ewing, M.N.R. Ashfold, Yu.A. Mankelevich, Measurement and modeling of a diamond deposition reactor: Hydrogen atom and electron number densities in an $\mathrm{Ar} / \mathrm{H} 2$ arc jet discharge, J. Appl. Phys. 97 (2005) 113306.

[18] R. Dux, K. Grützmacher, M.I. De La Rosa, B. Wende, Absolute determination of local ground-state densities of atomic hydrogen in nonlocal-thermodynamic-equilibrium environments by two-photon polarization spectroscopy, Phys. Rev. E. 51 (1995) 1416-1427.

[19] K. Grützmacher, M.I. de la Rosa, A.B. Gonzalo, M. Steiger, A. Steiger, Two-photon polarization spectroscopy applied for quantitative measurements of atomic hydrogen in atmospheric pressure flames, Appl. Phys. B. 76 (2003) 775-785.

[20] W.D. Kulatilaka, R.P. Lucht, S.F. Hanna, V.R. Katta, Two-color, two-photon laser-induced polarization spectroscopy (LIPS) measurements of atomic hydrogen in near-adiabatic, atmospheric pressure hydrogen/air flames, Combust. Flame. 137 (2004) 523-537. 
[21] S. Agrup, F. Ossler, M. Aldén, Measurements of collisional quenching of hydrogen atoms in an atmospheric-pressure hydrogen oxygen flame by picosecond laser-induced fluorescence, Appl. Phys. B Lasers Opt. 61 (1995) 479-487.

[22] J. Bittner, K. Kohse-Höinghaus, U. Meier, S. Kelm, Th. Just, Determination of absolute H atom concentrations in low-pressure flames by two-photon laser-excited fluorescence, Combust. Flame. 71 (1988) 41-50.

[23] U. Meier, J. Bittner, K. Kohse-Höinghaus, T. Just, Discussion of two-photon laser-excited fluorescence as a method for quantitative detection of oxygen atoms in flames, Symp. Int. Combust. 22 (1989) 1887 1896.

[24] J.E.M. Goldsmith, Multiphoton-excited fluorescence measurements of atomic hydrogen in low-pressure flames, Symp. Int. Combust. 22 (1989) 1403-1411.

[25] K. Kohse-Höinghaus, Laser techniques for the quantitative detection of reactive intermediates in combustion systems, Prog. Energy Combust. Sci. 20 (1994) 203-279.

[26] A.K. Patnaik, I. Adamovich, J.R. Gord, S. Roy, Recent advances in ultrafast-laser-based spectroscopy and imaging for reacting plasmas and flames, Plasma Sources Sci. Technol. 26 (2017) 103001.

[27] W.D. Kulatilaka, R.P. Lucht, S. Roy, J.R. Gord, T.B. Settersten, Detection of atomic hydrogen in flames using picosecond two-color two-photon-resonant six-wave-mixing spectroscopy, Appl. Opt. 46 (2007) 3921-3927.

[28] M. Ruchkina, P. Ding, A. Ehn, M. Aldén, J. Bood, Single-shot, spatially-resolved stand-off detection of atomic hydrogen via backward lasing in flames, Proc. Combust. Inst. 37 (2019) 1281-1288.

[29] A.H. Bhuiyan, A. Satija, S.V. Naik, R.P. Lucht, Development of two-color laser system for highresolution polarization spectroscopy measurements of atomic hydrogen, Opt. Lett. 37 (2012) 3564-3566.

[30] W.D. Kulatilaka, B.D. Patterson, J.H. Frank, T.B. Settersten, Comparison of nanosecond and picosecond excitation for interference-free two-photon laser-induced fluorescence detection of atomic hydrogen in flames, Appl. Opt. 47 (2008) 4672-4683.

[31] W.D. Kulatilaka, J.R. Gord, V.R. Katta, S. Roy, Photolytic-interference-free, femtosecond two-photon fluorescence imaging of atomic hydrogen, Opt. Lett. 37 (2012) 3051-3053.

[32] D.D. Cont-Bernard, M. Ruchkina, P. Ding, J. Bood, A. Ehn, D.A. Lacoste, Femtosecond two-photon laserinduced fluorescence imaging of atomic hydrogen in a laminar methane-air flame assisted by nanosecond repetitively pulsed discharges, Plasma Sources Sci. Technol. 29 (2020) 065011.

[33] C.A. Hall, W.D. Kulatilaka, J.R. Gord, R.W. Pitz, Quantitative atomic hydrogen measurements in premixed hydrogen tubular flames, Combust. Flame. 161 (2014) 2924-2932.

[34] I.A. Mulla, A. Dowlut, T. Hussain, Z.M. Nikolaou, S.R. Chakravarthy, N. Swaminathan, R. Balachandran, Heat release rate estimation in laminar premixed flames using laser-induced fluorescence of $\mathrm{CH} 2 \mathrm{O}$ and H-atom, Combust. Flame. 165 (2016) 373-383.

[35] A. Jain, Y. Wang, W.D. Kulatilaka, Effect of H-atom concentration on soot formation in premixed ethylene/air flames, Proc. Combust. Inst. 37 (2019) 1289-1296.

[36] H.W.P. van der Heijden, M.G.H. Boogaarts, S. Mazouffre, J.A.M. van der Mullen, D.C. Schram, Timeresolved experimental and computational study of two-photon laser-induced fluorescence in a hydrogen plasma, Phys. Rev. E. 61 (2000) 4402-4409.

[37] K. Niemi, V. Schulz von der Gathen, H.F. Döbele, Absolute calibration of atomic density measurements by laser-induced fluorescence spectroscopy with two-photon excitation, J. Phys. Appl. Phys. 34 (2001) $2330-2335$.

[38] M.G.H. Boogaarts, S. Mazouffre, G.J. Brinkman, H.W.P. van der Heijden, P. Vankan, J.A.M. van der Mullen, D.C. Schram, H.F. Döbele, Quantitative two-photon laser-induced fluorescence measurements of atomic hydrogen densities, temperatures, and velocities in an expanding thermal plasma, Rev. Sci. Instrum. 73 (2002) 73-86.

[39] B.N. Ganguly, J.W. Parish, Absolute H atom density measurement in pure methane pulsed discharge, Appl. Phys. Lett. 84 (2004) 4953-4955.

[40] C. Winters, V. Petrishchev, Z. Yin, W.R. Lempert, I.V. Adamovich, Surface charge dynamics and OH and $\mathrm{H}$ number density distributions in near-surface nanosecond pulse discharges at a liquid / vapor interface, J. Phys. Appl. Phys. 48 (2015) 424002. 
[41] P. Desgroux, L. Gasnot, B. Crunelle, J.F. Pauwels, CH3 detection in flames using photodissociationinduced fluorescence, Symp. Int. Combust. 26 (1996) 967-974.

[42] L. Gasnot, P. Desgroux, J.F. Pauwels, L.R. Sochet, Improvement of two-photon laser induced fluorescence measurements of H- and O-atoms in premixed methane/air flames, Appl. Phys. B. 65 (1997) 639-646.

[43] J.E.M. Goldsmith, Photochemical effects in 205-nm, two-photon-excited fluorescence detection of atomic hydrogen in flames, Opt. Lett. 11 (1986) 416-418.

[44] W. Kulatilaka, J. Frank, B. Patterson, T. Settersten, Analysis of 205-nm photolytic production of atomic hydrogen in methane flames, Appl. Phys. B Lasers Opt. 97 (2009) 227-242.

[45] W.D. Kulatilaka, J.H. Frank, T.B. Settersten, Interference-free two-photon LIF imaging of atomic hydrogen in flames using picosecond excitation, Proc. Combust. Inst. 32 I (2009) 955-962.

[46] B. Li, D. Zhang, X. Li, Q. Gao, M. Yao, Z. Li, Strategy of interference-free atomic hydrogen detection in flames using femtosecond multi-photon laser-induced fluorescence, Int. J. Hydrog. Energy. 42 (2017) 3876-3880.

[47] J.E.M. Goldsmith, Two-photon-excited stimulated emission from atomic hydrogen in flames, J. Opt. Soc. Am. B Opt. Phys. 6 (1989) 1979-1985.

[48] B.L. Preppernau, K. Pearce, A. Tserepi, E. Wurzberg, T.A. Miller, Angular momentum state mixing and quenching of $n=3$ atomic hydrogen fluorescence, Chem. Phys. 196 (1995) 371-381.

[49] U. Meier, K. Kohse-Höinghaus, T. Just, H and O atom detection for combustion applications: study of quenching and laser photolysis effects, Chem. Phys. Lett. 126 (1986) 567-573.

[50] W. Juchmann, J. Luque, J.B. Jeffries, Two-photon laser-induced fluorescence of atomic hydrogen in a diamond-depositing dc arcjet, Appl. Opt. 44 (2005) 6644-6652.

[51] M.J. Wouters, J. Khachan, I.S. Falconer, B.W. James, Production and loss of H atoms in a microwave discharge in, J. Phys. Appl. Phys. 31 (1998) 2004-2012.

[52] A. Goehlich, T. Kawetzki, H.F. Döbele, On absolute calibration with xenon of laser diagnostic methods based on two-photon absorption, J. Chem. Phys. 108 (1998) 9362-9370.

[53] D. Elliott, E. Scime, Z. Short, Novel xenon calibration scheme for two-photon absorption laser induced fluorescence of hydrogen, Rev. Sci. Instrum. 87 (2016) 11E504.

[54] J. Jolly, J.-P. Booth, Atomic hydrogen densities in capacitively coupled very high-frequency plasmas in H2: Effect of excitation frequency, J. Appl. Phys. 97 (2005) 103305.

[55] M.E. Galante, R.M. Magee, E.E. Scime, Two photon absorption laser induced fluorescence measurements of neutral density in a helicon plasma, Phys. Plasmas. 21 (2014) 055704.

[56] M. Mrkvičková, J. Ráhel', P. Dvořák, D. Trunec, T. Morávek, Fluorescence (TALIF) measurement of atomic hydrogen concentration in a coplanar surface dielectric barrier discharge, Plasma Sources Sci. Technol. 25 (2016) 055015.

[57] J.B. Schmidt, S. Roy, W.D. Kulatilaka, I. Shkurenkov, I.V. Adamovich, W.R. Lempert, J.R. Gord, Femtosecond, two-photon-absorption, laser-induced-fluorescence (fs-TALIF) imaging of atomic hydrogen and oxygen in non-equilibrium plasmas, J. Phys. Appl. Phys. 50 (2017) 015204.

[58] N. Lamoureux, P. Desgroux, Direct quantification of O-atom in methane low-pressure flames by using two-photon LIF, Proc. Combust. Inst. in press (n.d.). https://doi.org/doi.org/10.1016/j.proci.2020.06.167.

[59] R.J. Kee, J.F. Grcar, M.D. Smooke, J.A. Miller, A Fortran Program for Modeling Steady Laminar OneDimensional Premixed Flames, Sandia National Laboratories, Livermore, 1985.

[60] N. Lamoureux, H. El Merhubi, L. Pillier, S. de Persis, P. Desgroux, Modeling of NO formation in low pressure premixed flames, Combust. Flame. 163 (2016) 557-575.

[61] N. Lamoureux, P. Desgroux, A. El Bakali, J.F. Pauwels, Experimental and numerical study of the role of $\mathrm{NCN}$ in prompt-NO formation in low-pressure $\mathrm{CH}_{4} / \mathrm{O}_{2} / \mathrm{N}_{2}$ and $\mathrm{C}_{2} \mathrm{H}_{2} / \mathrm{O}_{2} / \mathrm{N}_{2}$ flames, Combust. Flame. 157 (2010) 1929-1941.

[62] A. Kramida, Y. Ralchenko, J. Reader, NIST ASD Team, NIST Atomic Spectra Database (version 5.7.1), Https://Physics.Nist.Gov/Asd. (2019).

[63] A.E. Kramida, A critical compilation of experimental data on spectral lines and energy levels of hydrogen, deuterium, and tritium, At. Data Nucl. Data Tables. 96 (2010) 586-644.

[64] W.L. Wiese, J.R. Fuhr, Accurate Atomic Transition Probabilities for Hydrogen, Helium, and Lithium, J. Phys. Chem. Ref. Data. 38 (2009) 565-720. 
[65] J.E. Sansonetti, W.C. Martin, Handbook of Basic Atomic Spectroscopic Data, J. Phys. Chem. Ref. Data. 34 (2005) 1559-2259.

[66] E.B. Saloman, Energy Levels and Observed Spectral Lines of Krypton, Kr I through Kr XXXVI, J. Phys. Chem. Ref. Data. 36 (2007) 215-386.

[67] K. Dzierżęga, U. Volz, G. Nave, U. Griesmann, Accurate transition rates for the 5p-5s transitions in Kr I, Phys. Rev. A. 62 (2000) 022505.

[68] J. Kielkopf, K. Myneni, Excitation transfer due to neutral collisions in excited states of atomic hydrogen, J. Phys. B At. Mol. Phys. 20 (1987) 2467-2479.

[69] J. Bittner, K. Kohse-Höinghaus, U. Meier, Th. Just, Quenching of two-photon-excited H(3s, 3d) and O(3p 3P2,1,0) atoms by rare gases and small molecules, Chem. Phys. Lett. 143 (1988) 571-576.

[70] T.I. Quickenden, S.M. Trotman, J.A. Irvin, D.F. Sangster, H2O quenching of the transitions $H(n=3 \rightarrow n=2)$ and $\mathrm{O}(3 \mathrm{p} 3 \mathrm{P} \rightarrow 3 \mathrm{~s} 3 \mathrm{~S} 0)$ in pulse radiolytically excited water vapor, J. Chem. Phys. 71 (1979) 497-501.

[71] R.S.F. Chang, H. Horiguchi, D.W. Setser, Radiative lifetimes and two-body collisional deactivation rate constants in argon for $\operatorname{Kr}(4 p 55 p)$ and $\operatorname{Kr}\left(4 p 55 p^{\prime}\right)$ states, J. Chem. Phys. 73 (1980) 778-790.

[72] K. Wang, Y. Wang, J. Wang, Z. Yi, W.D. Kulatilaka, A.V. Sokolov, M.O. Scully, Femtosecond pumpprobe studies of atomic hydrogen superfluorescence in flames, Appl. Phys. Lett. 116 (2020) 201102.

[73] A.F.H. van Gessel, S.C. van Grootel, P.J. Bruggeman, Atomic oxygen TALIF measurements in an atmospheric-pressure microwave plasma jet with in situ xenon calibration, Plasma Sources Sci. Technol. 22 (2013) 055010.

[74] J.B. Schmidt, B. Sands, J. Scofield, J.R. Gord, S. Roy, Comparison of femtosecond- and nanosecond-twophoton-absorption laser-induced fluorescence (TALIF) of atomic oxygen in atmospheric-pressure plasmas, Plasma Sources Sci. Technol. 26 (2017) 055004. 
List of Figure captions

Fig. 1. TPLIF excitation and collection schemes of atomic $\mathrm{H}$ and $\mathrm{Kr}$, from NIST [62]. The bold arrows indicate the involved transitions both in absorption (two-photon) and in emission. The dashed arrows indicate the possible transitions according to a fast mixing between the sublevels $n=3$ in the case of $\mathrm{H}[48,68]$. The thin arrows indicate the other fluorescence transitions occurring from the level $n=3$ in the case of Kr. See details in the Supplementary Materials

Fig. 2. Squared of temporal laser profile scaled with the normalized H-TPLIF decay profile collected at $p=2.1 \mathrm{kPa}$ with PMT R2257. The fit is a convolution of the simulated squared of the laser pulse shape and an exponential decay function.

Fig. 3: Stern-Volmer plots of H-TPLIF measured using PMT R2059 and PMT R2257 in a stoichiometric $\mathrm{CH}_{4} / \mathrm{O}_{2}$ flame diluted with $58 \%$ N2.

Fig. 4. Stern-Volmer plot of Kr measured with the PMT R2257 in the burned gases of a flame with the same gas flow rates as Flame CH4_cal (Table 1).

Fig. 5. Stern-Volmer plots for $\mathrm{H}$-atom measured in the burned gases of stoichiometric $\mathrm{CH}_{4} / \mathrm{O}_{2}$ flames (gas flow rates reported in Table 1 for CH4(100) and CH4_cal) (a) with PMT R2257 (b) with PMT R2059. Linear regression coefficients are reported beside the lines.

Fig. 6. H-atom mole fraction and fluorescence decay rates $(A+Q)$ profiles along the HAB of flame $\mathrm{CH} 4$ _cal.

Fig. 7. H-atom mole fraction profiles in the nitrogen-diluted flames at $p=5.3 \mathrm{kPa}$. Symbols: experimental points, lines: simulated with NOMecha2.0 [60]. For clarity, only the error bar for $\phi=1$ is shown.

Fig. 8. Comparison between the experimental $\mathrm{H}$-atom mole fraction $\chi \mathrm{H}$ and the calculated value using the equilibrium constant of reactions R1-R3, along the 3 flames (a) $\phi=0.8$, (b) $\phi=1$, (c) $\phi=1.25$ stabilized at $p=5.33 \mathrm{kPa}$. 
Figure 1: preferentially double column
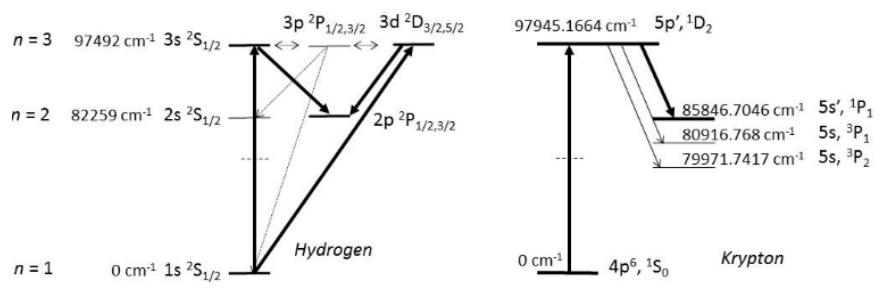
Figure 2

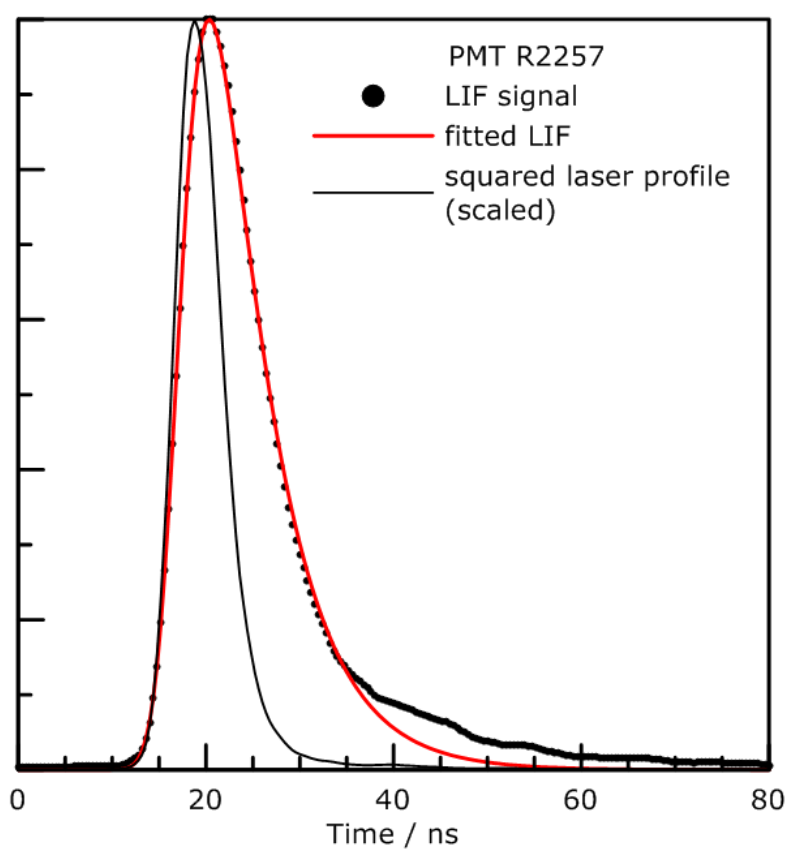


Figure 3

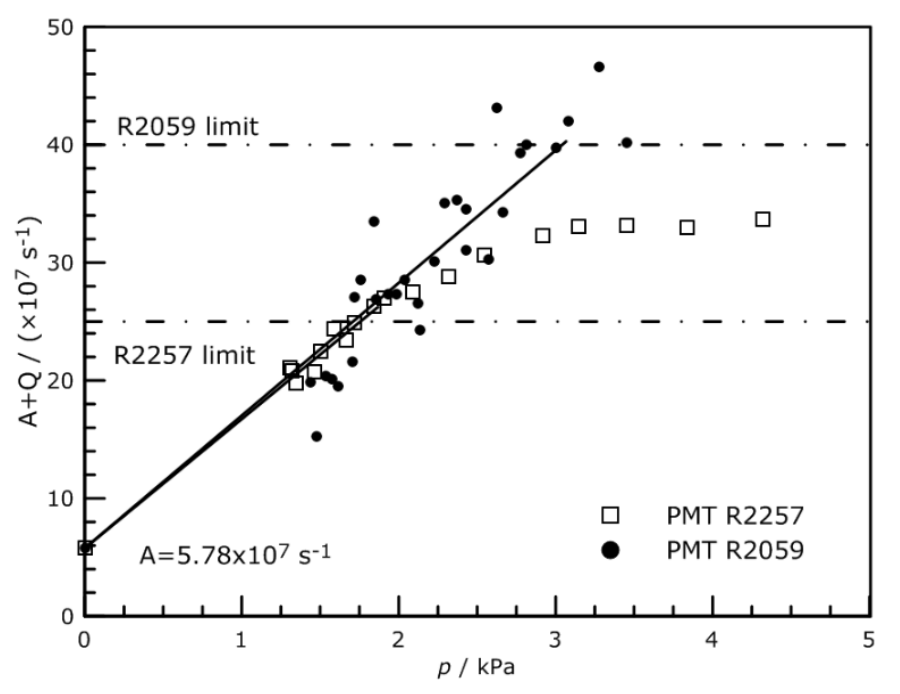


Figure 4

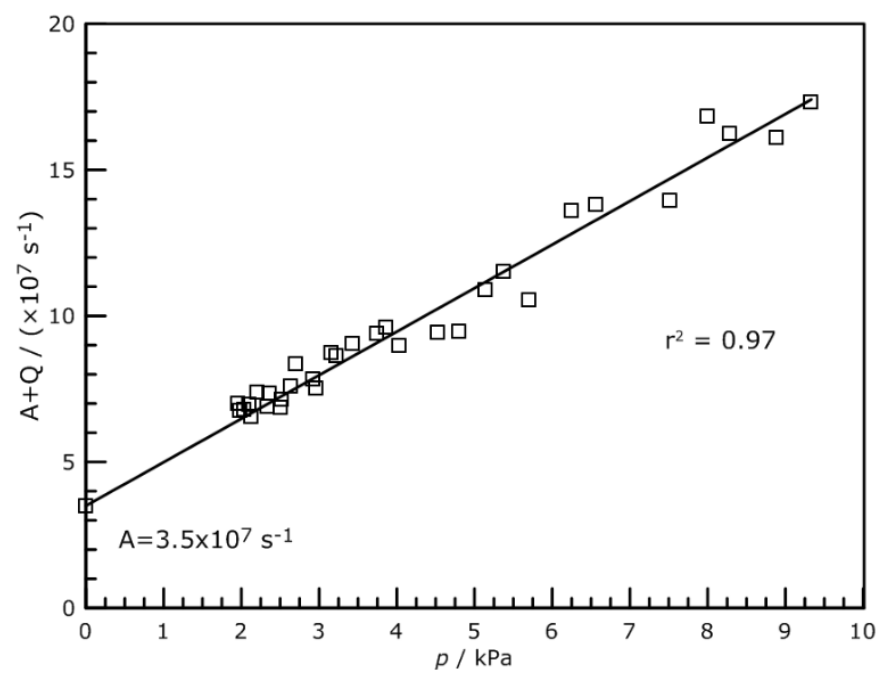


Figure 5: consists of Figure 5a and figure 5b
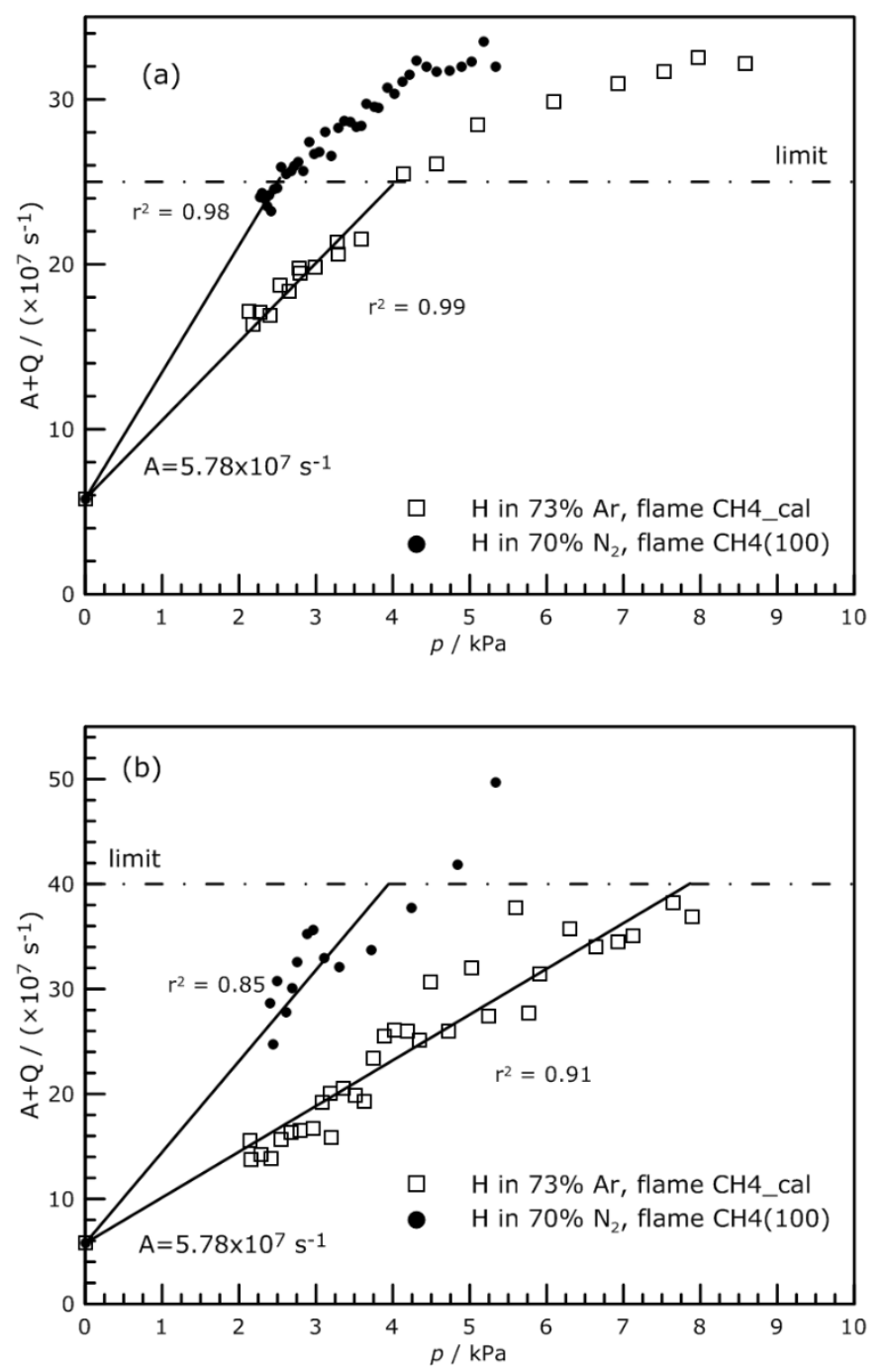
Figure 6

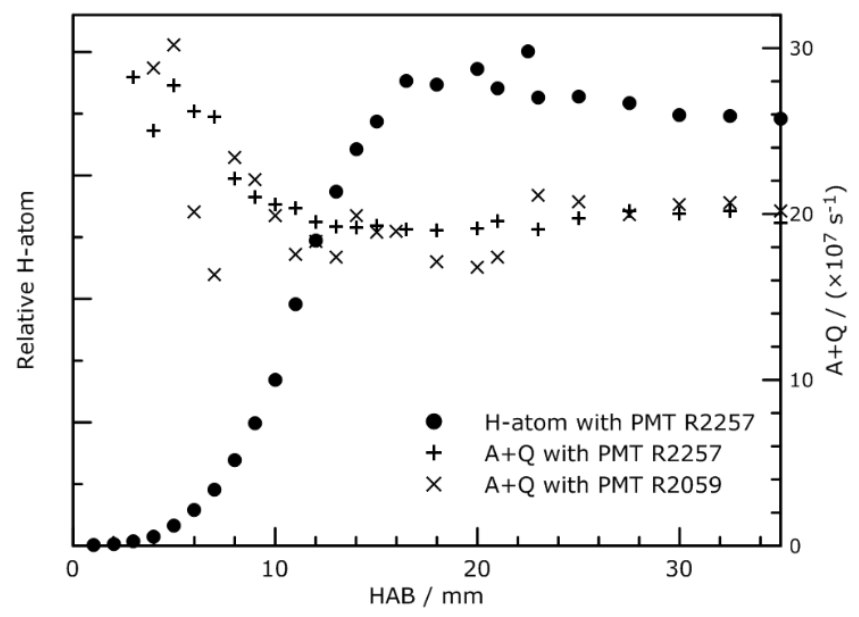


Figure 7

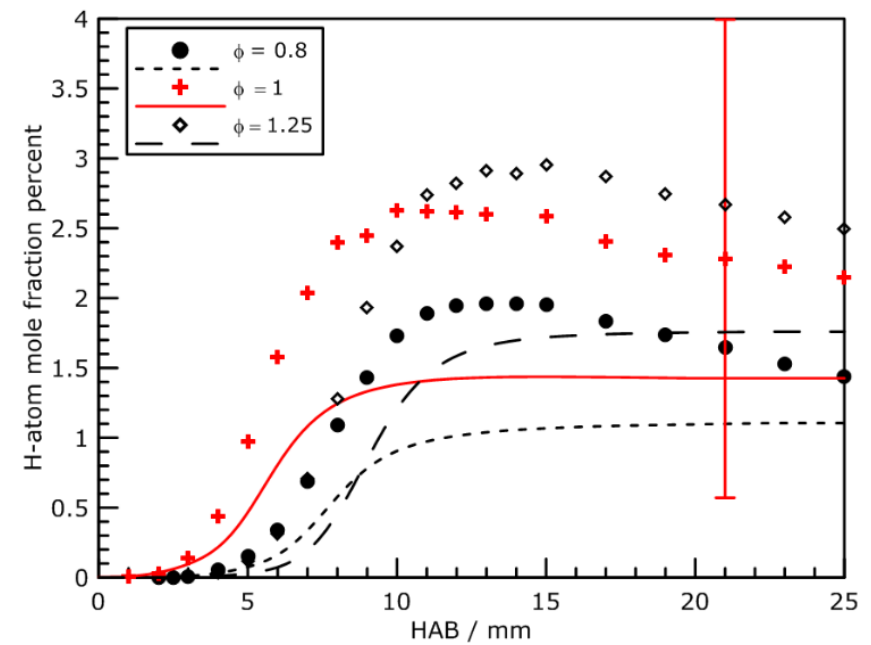


Figure 8: consists of figure $8 \mathrm{a}+$ figure $8 \mathrm{~b}+$ figure $8 \mathrm{c}$ (can be put side by side on a double column by applying adequate reduction)
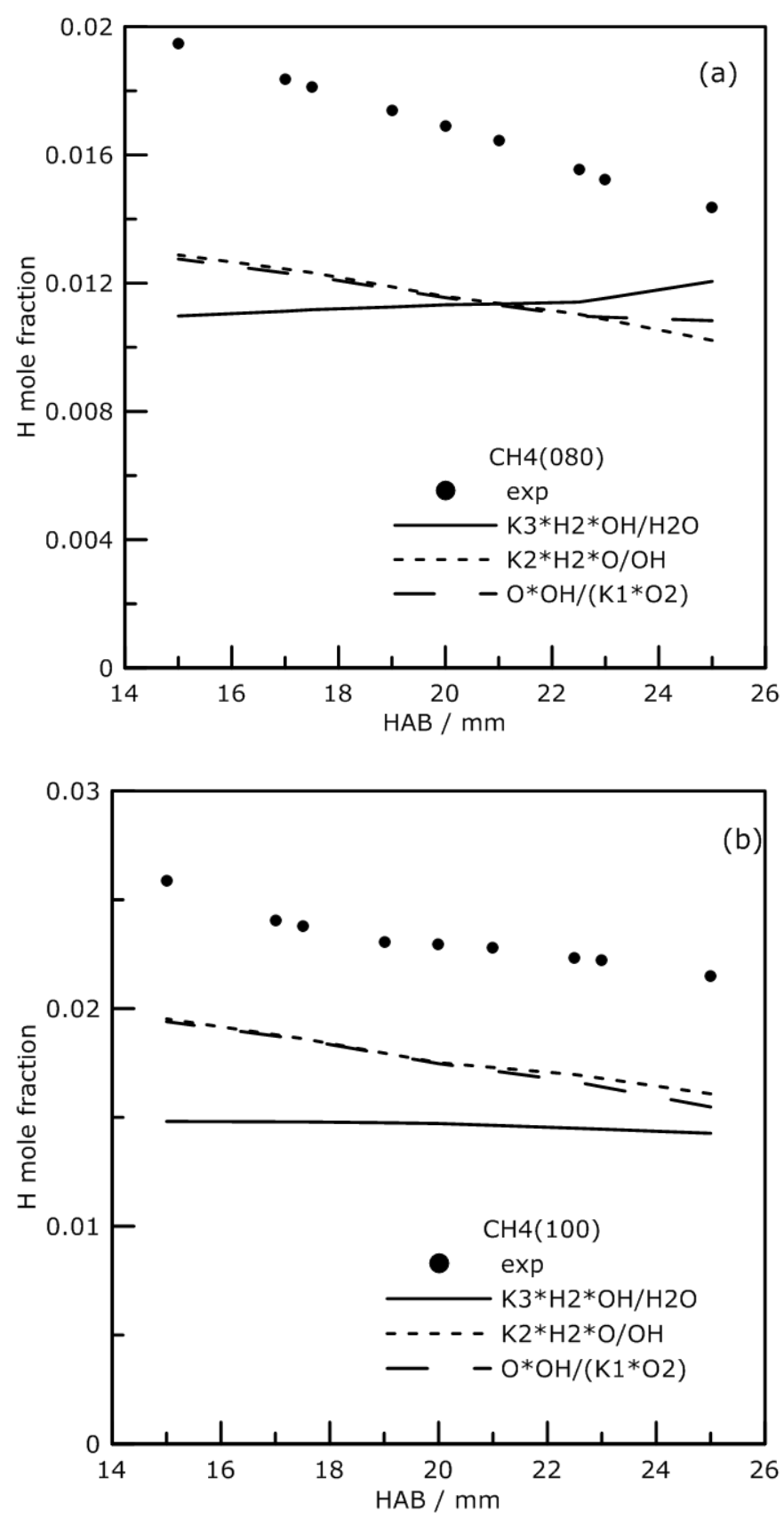


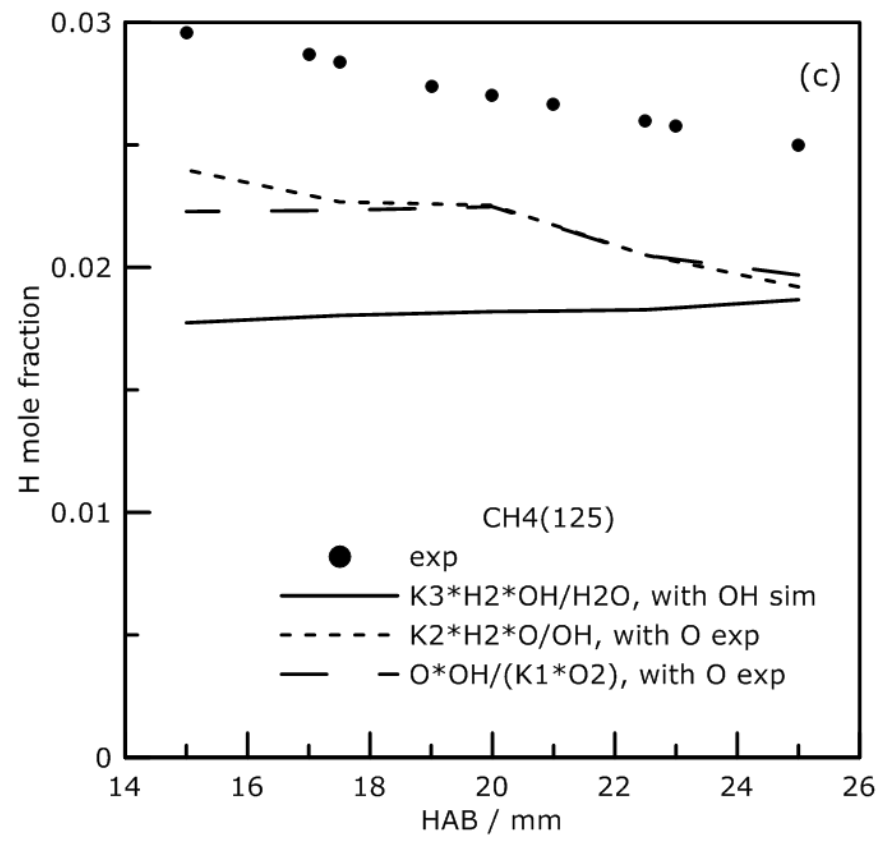

